\title{
Effects of Wind Direction on the Airflow and Pollutant Dispersion inside a Long Street Canyon
}

\author{
Yuan-Dong Huang ${ }^{1 *}$, Ren-Wei Hou ${ }^{1}$, Ze-Yu Liu ${ }^{1}$, Ye Song ${ }^{1}$, Peng-Yi Cui ${ }^{1}$, Chang-Nyung Kim ${ }^{2}$ \\ ${ }^{1}$ School of Environment and Architecture, University of Shanghai for Science and Technology, Shanghai 200093, China \\ ${ }^{2}$ College of Engineering, Kyung Hee University, Yongin 449-701, Korea
}

\begin{abstract}
This study investigates the effects of wind direction on the airflow and pollutant dispersion inside a long street canyon using computational fluid dynamics (CFD). A 3D CFD model for predicting the flow and dispersion in a canyon is first developed using the FLUENT code and then validated against wind tunnel experiments. Then, the airflow and traffic pollutant dispersion in an isolated canyon with a street-length-to-building-height ratio of 10 are numerically simulated for seven wind directions $\left(\alpha=0^{\circ}, 15^{\circ}, 30^{\circ}, 45^{\circ}, 60^{\circ}, 75^{\circ}\right.$ and $90^{\circ}$, where $\alpha$ is the angle between the approaching flow and street axis). The results demonstrate that the mean $(\overline{\mathrm{ACH}})$ and turbulent $\left(\mathrm{ACH}^{\prime}\right)$ air exchange rates (ACHs) for the canyon are close when $\alpha=0^{\circ}, 15^{\circ}, 30^{\circ}, 45^{\circ}$ and $60^{\circ}$, whereas the magnitude of $\mathrm{ACH}^{\prime}$ is significantly greater than that of $\overline{\mathrm{ACH}}$ when $\alpha=75^{\circ}$ and $90^{\circ}$. Additionally, the ACH reaches its maximum and minimum values when $\alpha=30^{\circ}$ and $90^{\circ}$, respectively. The computed velocity and concentration fields clearly reveal the variation in the in-canyon flow pattern and pollutant distributions on the canyon walls and footpaths due to the wind direction. Evaluating the maximum, minimum and average concentrations on the canyon walls and footpaths for each of the seven wind directions, we determine: On the leeward-oriented wall, the wall-averaged concentration increases greatly with $\alpha$, and the values of the wall-maximum are highest when $\alpha=75^{\circ}$ and lowest when $\alpha=0^{\circ}$. By contrast, on the windward-oriented wall, both the wall-averaged and wall-maximum concentrations are highest when $\alpha=0^{\circ}$. Finally, at the human respiration height, the highest concentration on the footpath next to the leeward-oriented wall occurs when $\alpha=75^{\circ}$, whereas the highest concentration on the footpath close to the windward-oriented wall is observed when $\alpha=0^{\circ}$.
\end{abstract}

Keywords: Wind direction; Airflow; Pollutant dispersion; Street canyon; CFD.

\section{INTRODUCTION}

Street canyons are the basic geometrical units of urban areas. Investigations of wind flow and traffic pollutant dispersion inside street canyons have been a focal point in field of atmospheric environmental studies. Field measurements (e.g., Richmond-Bryant et al., 2011; Karra et al., 2017), wind tunnel (WT) experiments (e.g., Gromke and Ruck, 2007; Huang et al., 2016a; Allegrini, 2018) and computational fluid dynamics (CFD) techniques (e.g., Salim et al., 2011; Huang et al., 2016b; Chew et al., 2018) have all been utilized for the study of flow and dispersion within street canyons.

Most previous studies on flow and pollutant dispersion in street canyons focused on the cases with an ambient wind direction perpendicular to the street axis, because this is generally assumed to be the worst case for pollutant

\footnotetext{
${ }^{*}$ Corresponding author.

E-mail address: huangyuandong@tsinghua.org.cn
}

dispersion (Soulhac and Salizzoni, 2010). A few studies have already been conducted to examine the flow and pollutant dispersion inside street canyons under the ambient wind blowing parallel and/or oblique to the street axis. For instance, Kastner-Klein and Plate (1999) performed a WT study of concentration fields in street canyons. In their experiments, seven different wind directions (i.e., parallel and perpendicular winds as well as five oblique winds) were considered and the pollutant concentrations were obtained at two near-ground points on the downstream part of the leeward-oriented wall of the canyon. Gromke and Ruck (2012) conducted a series of WT experiments to investigate the pollutant dispersion in street canyons of different aspect ratios with/without avenues of trees. In their experiments, cases with the parallel and perpendicular wind directions as well as the oblique wind direction with $\alpha=45^{\circ}$ (where $\alpha$ is the angle between the ambient wind flow and the street axis) were considered and the pollutant concentration distributions on the canyon walls were obtained under each of the three wind directions. Based on the WT experiments performed by Gromke and Ruck (2012), the flow and pollutant dispersion within the reduced-scale canyon under 
the wind directions with $\alpha=0^{\circ}, 45^{\circ}$, and $90^{\circ}$ were also examined using the CFD approach by several researchers (Jean et al., 2015). Salizzoni and Soulhac (2010) carried out a study on the dispersion in a street canyon for a parallel wind. Their results indicated that for a critical length of the street the ground level concentrations can be higher than those observed in a street canyon whose axis is perpendicular to the external-wind direction.

As noted above, a few studies have been undertaken to investigate the flow and traffic-related pollutant dispersion inside street canyons under different wind directions. However, the situations with oblique wind directions (except for $\alpha=45^{\circ}$ ) were scarcely considered in the previous studies on the flow field and pollutant distribution in canyons. Air exchange rate $(\mathrm{ACH})$ for a street canyon is a crucial index for evaluating canyon ventilation. Liu et al. (2005) and Li et al. (2005) first introduced air exchange rate $(\mathrm{ACH})$ for the evaluation of ventilation in 2D street canyons. Then Hang et al. (2009) first adopted ACH for ventilation assessment in 3D urban models. Furthermore, the impacts of ambient wind directions on $\mathrm{ACH}$ were investigated in 3D urban models with different overall urban forms (Hang et al., 2009), court-yard settings (Moonen et al., 2012), semi-open street roofs (Hang et al., 2013), building clusters with the same building packing density (Lin et al., 2014), and urban open space (Wang et al., 2017). However, the influence of ambient wind directions on $\mathrm{ACH}$ in long street canyon models has not been well documented. From a point of view regarding urban air quality and urban planning, the important evaluation parameters are maximum, minimum and average concentration levels on canyon walls and in canyon footpaths. However, the most favorable and unfavorable wind directions with respect to the pollutant concentration levels on canyon walls or in canyon footpaths have not been identified distinctly. Therefore, obviously, further studies are still necessary to clarify the effects of ambient wind direction on wind flow pattern and pollutant dispersion inside street canyons.

This study aims to investigate numerically the impacts of ambient wind direction on the flow and pollutant dispersion inside a long street canyon. For this purpose, a 3D reducedscale model of a long isolated canyon is applied and gaseous pollutants from vehicle emissions are analyzed. Based on the Reynolds-Averaged Navier-Stokes (RANS) equations equipped with the standard $k$ - $\varepsilon$ turbulence closure scheme and the advection-diffusion equation for chemical species, a 3D CFD model for flow and pollutant dispersion inside a street canyon is first established using the CFD code (ANSYS, 2009), then validated with the WT measured data. After this, the flow and pollutant dispersion are simulated numerically inside an isolated canyon with a street-length-tobuilding-height ratio of 10. In the simulations, seven ambient wind directions (the parallel and perpendicular winds as well as five oblique winds) are considered. The $\mathrm{ACH}$ for the canyon, the velocity and concentration fields inside the canyon are obtained under seven wind directions. They are analyzed systematically to elucidate the variations of flow pattern and traffic pollutant distribution inside a long isolated canyon with the ambient wind direction. Furthermore, the most favorable and unfavorable wind directions are identified from the investigation of concentration levels on the canyon walls and in the canyon footpaths.

\section{STREET CANYON CONFIGURATION USED IN THE CFD SIMULATIONS}

The computational street canyon configuration is constructed based on a reduced-scale isolated street canyon model (scale $M=1: 150$ ) adopted in the WT experiments performed in an atmospheric boundary layer wind tunnel of University of Karlsruhe, Germany (see the internet database CODASC, www.codasc.de).

Fig. 1 sketches the $3 \mathrm{D}$ isolated canyon configuration adopted in the present CFD investigations, which consists of two identical buildings arranged parallel to each other. Each building has a square cross section (i.e., $W_{A}=W_{B}=H$, where $W_{A}$ is the width of Building $\mathrm{A}, W_{B}$ is the width of Building $\mathrm{B}$ and $H$ is the building height). The street width

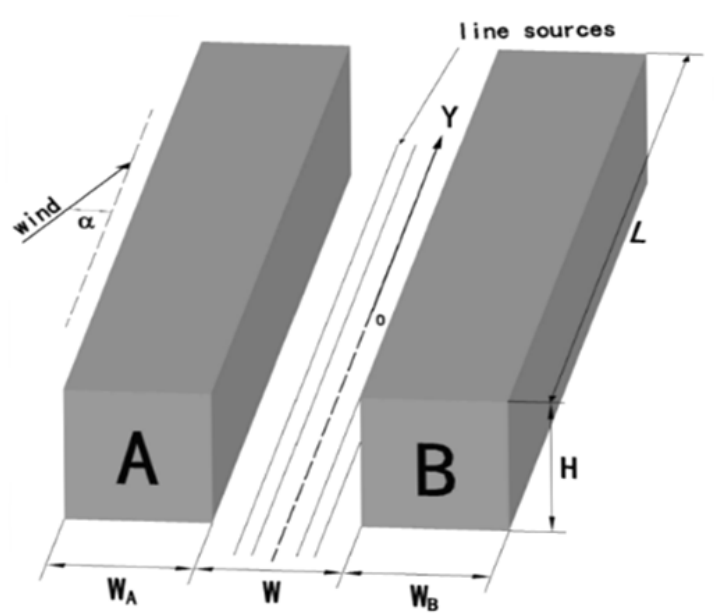

(a)

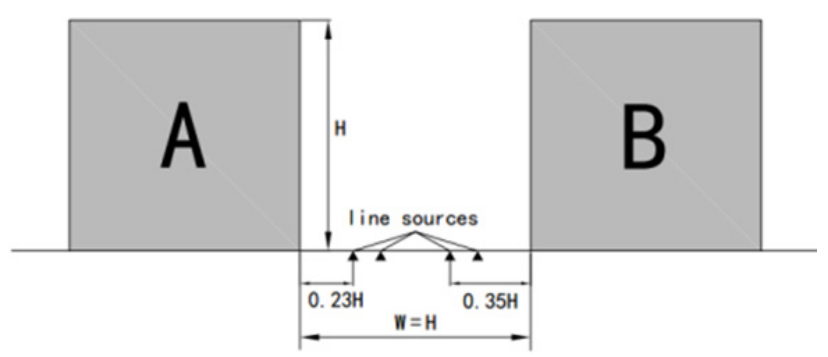

(b)

Fig. 1. Schematic sketches of the street canyon configuration $\left(W_{\mathrm{A}}=W_{\mathrm{B}}=H\right)$ : (a) street canyon geometry; (b) positions of the four line sources put on the street floor. 
$W$ is equal to the building height (i.e., a canyon with an aspect ratio of $W / H=1$ is formed). The street length $L$ is ten times the building height, and thus a long canyon $(L / H$ $>7$ ) is utilized, following the usual classification of street canyons (Vardoulakis et al., 2003). Four parallel line sources, which release continuously sulfur hexafluoride $\left(\mathrm{SF}_{6}\right)$ tracer gas at a constant rate, are placed on the street floor to mimic the vehicular exhaust emissions on a 4-lane road. The height and width of each line source are both $0.005 \mathrm{~m}$ (i.e., $0.75 \mathrm{~m}$ in the full scale). Each line source extends beyond the street ends by $0.92 H$ on each side (i.e., $l=L+2 \times 0.92 H$, where $l$ is the length of each line source) in order to account for the traffic exhausts emitted on the sidewise street intersections (Gromke et al., 2008; Salim et al., 2011a).

For evaluating the effects of wind direction on airflow and pollutant dispersion in a long isolated street canyon, seven different wind directions (i.e., $\alpha=0^{\circ}, 15^{\circ}, 30^{\circ}, 45^{\circ}$, $60^{\circ}, 75^{\circ}$ and $90^{\circ}$, where $\alpha$ is the angle between the undisturbed approaching flow and the canyon length axis) are considered. In order to analyze easily the flow pattern and pollutant distribution on the different vertical cross sections of the canyon, the street floor center axis ( $Y$ axis) is defined, with $Y=0$ at the center of the canyon floor.

For each of the seven different wind directions (here, each wind direction corresponds to a specific simulation case), the building height $H$ is $0.12 \mathrm{~m}$ (i.e., $18 \mathrm{~m}$ in the full scale) and the flow velocity $U_{H}$ at the building height $H$ in the undisturbed approaching flow is $4.70 \mathrm{~m} \mathrm{~s}^{-1}$. The Reynolds number $(R e)$, defined with $H$ and $U_{H}$, is approximately 37,200 .

\section{CFD MODEL AND ITS VALIDATION}

\section{CFD Model}

\section{Governing Equations for Wind Flow and Gaseous Pollutant Dispersion}

The wind flow in and outside the street canyons can be regarded as an incompressible flow. Moreover, the thermal effects due to solar heating in the canyons and the effects of traffic-induced turbulence are not taken into account herein. For the isolated canyon scenarios in Fig. 1, the governing equations for airflow are the $3 \mathrm{D}$, steady, incompressible, and isothermal RANS equations with the standard $k-\varepsilon$ model.

Large eddy simulation (LES) performs better than RANS approaches in predicting turbulent airflows (Salim et al., 2011a; Li et al., 2015; Zhong et al., 2015; Sha et al., 2018). However, LES requires much longer time of computation than RANS (Salim et al., 2011a; Lin et al., 2014). Furthermore, it is considerably more difficult to generate appropriate time-dependent wall and inlet boundary conditions for LES than for RANS (Tabor and Baba-Ahmadi, 2010; Sha et al., 2018).

Since RANS turbulence models are more time-saving than LES and they provide reasonable results for mean flows and the spatial average flow properties (Yoshie et al., 2007; Lin et al., 2014), this study applies RANS turbulence models for evaluating in-canyon turbulent flows. According to the literature (Yoshie et al., 2007; Tominaga et al., 2008; Lin et al., 2014), the modified $k-\varepsilon$ models (such as the
RNG $k-\varepsilon$ model) are capable of correcting the drawback of the standard $k-\varepsilon$ model which greatly overestimates the turbulent kinetic energy at the impinging regions of buildings. However, the modified $k-\varepsilon$ models not only fail to predict the sizes of reattachment lengths behind buildings, but also underestimate the velocity in weak wind regions (Lin et al., 2014). In addition, many previous studies have evaluated the standard $k-\varepsilon$ model to simulate wind flow and pollutant dispersion inside street canyons and have found good agreement between CFD results and WT measurements (e.g., Huang et al., 2009; Ng and Chau, 2014; Sha et al., 2018). Therefore, despite its limitation in over-predicting the turbulence in flow-separation regions, this study still adopts the standard $k-\varepsilon$ model to simulate the isothermal steady-state wind flows inside the street canyons, which is validated well by WT data herein.

For the simulation of gaseous pollutant dispersion in the street canyon, a steady advection-diffusion equation for an inert and passive chemical species is utilized (Huang et al., 2009), giving:

$$
\begin{aligned}
& u \frac{\partial C^{\beta}}{\partial x}+v \frac{\partial C^{\beta}}{\partial y}+w \frac{\partial C^{\beta}}{\partial z}=\frac{\partial}{\partial x}\left(\left(D_{m}^{\beta}+\frac{v_{t}}{S c_{t}}\right) \frac{\partial C^{\beta}}{\partial x}\right) \\
& +\frac{\partial}{\partial y}\left(\left(D_{m}{ }^{\beta}+\frac{v_{t}}{S c_{t}}\right) \frac{\partial C^{\beta}}{\partial y}\right)+\frac{\partial}{\partial z}\left(\left(D_{m}{ }^{\beta}+\frac{v_{t}}{S c_{t}}\right) \frac{\partial C^{\beta}}{\partial z}\right)+S
\end{aligned}
$$

where $u, v$ and $w$ are the time-averaged velocity components in $x$-, $y$ - and $z$-directions, respectively. $C^{\beta}$ is the time-averaged concentration of chemical species $\beta$, $D_{m}^{\beta}$ is the molecular diffusivity for the species $\beta$, $v_{t}=C_{\mu} \frac{k^{2}}{\varepsilon}$ is the turbulent eddy viscosity, where $k$ is the turbulent kinetic energy, $\varepsilon$ is the turbulent dissipation rate, and $C_{\mu}=0.09$ is an empirical constant. $S$ is the pollutant source term. $S c_{t}$ is the turbulent Schmidt number. Gromke and Blocken (2015) performed CFD simulations with $S c_{t}=$ $0.3,0.5$ and 0.7 to investigate the pollutant dispersion inside street canyons. They found that an appropriate value of $S c_{t}$ is 0.5 for modeling dispersion within street canyons. In the current study, the CFD simulations are performed with $S c_{t}=$ 0.3 , which can reproduce the wind tunnel experimental data reasonably well (Section 3.2).

\section{Computational Domain and Boundary Conditions}

Fig. 2 shows the computational domain for the CFD simulation setup. The guideline of Tominaga et al. (2008) is followed to define the domain size. Here, the case with $\alpha=45^{\circ}$ is selected as an example. For all the seven simulation cases, the computational domain covers a horizontal area of $30 \mathrm{H} \times 24 \mathrm{H}$ and a vertical height of $8 \mathrm{H}$. For each case, the shortest distance is $8 H$ from Building A to the inlet plane, $(22-10 \cos \alpha-3 \sin \alpha) H$ (e.g., $12.8 H$ for the case with $\alpha=45^{\circ}$ ) from the building B to the outlet plane, and $(12-5 \sin \alpha-1.5 \cos \alpha) H$ (e.g., $7.4 H$ for the case with $\alpha=$ $45^{\circ}$ ) from the building to the lateral side of the domain. In each case, a rectangular coordinate system with the origin 


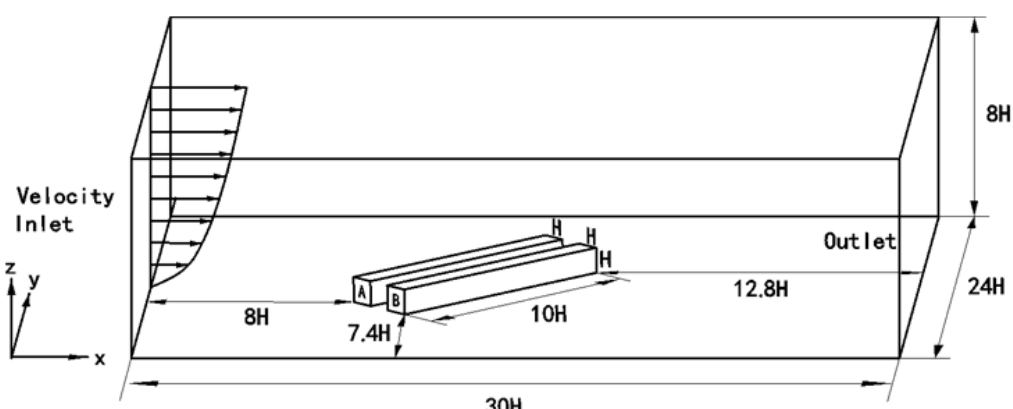

(a)

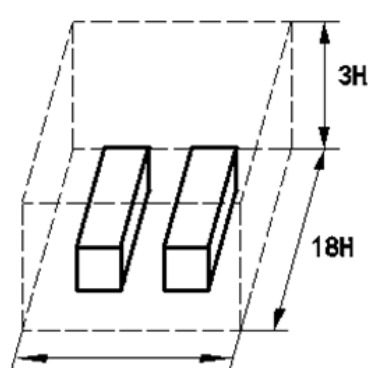

$5 \mathrm{H}$

Fig. 2. Computational domain for the CFD simulation setup: (a) the entire domain; (b) the inner zone defining the vicinity of the canyon.

located on the ground is used: The positive $x$-axis is along the approaching wind direction and the $z$-axis is perpendicular to the ground.

At the inlet boundary, the vertical profiles for wind velocity, turbulent kinetic energy and turbulent dissipation rate are specified (see Section 3.2). A zero-gradient condition is assigned to the domain outlet. A symmetric boundary condition is used at the top and on the two lateral sides of the domain. A non-slip condition with the standard wall function (Launder and Spalding, 1974) is imposed at all the solid boundaries. For the line sources, the volume flow rate for $\mathrm{SF}_{6}$ is provided.

\section{Grid Characteristics and Numerical Scheme}

The computational domain is discretized using tetrahedral grids. The entire domain is divided into two zones: the inner and outer zones. The inner zone defining the vicinity of the street canyon is $5 H$ (length) $\times 18 H$ (width) $\times 3 H$ (height) (see Fig. 2(b))

In the inner zone, the grid cells with an edge length of $0.005 \mathrm{~m}$ (i.e., $0.0417 H$ ) are placed on the solid surfaces. The grid cells are expanded from the solid surfaces towards the border between the inner and outer zones. The expansion ratio between two consecutive cells is limited to 1.08 and the largest grid cell has an edge length of $0.02 \mathrm{~m}$. In the outer zone, the equal-sized grid cells with an edge length of $0.08 \mathrm{~m}$ are created. Clearly, the grid cells are concentrated near the buildings (approximately 70 to $80 \%$ of the total cells, depending on the various simulation cases, are placed in the inner zones). Depending on the wind direction, the total number of grid cells ranges 3.0-3.7 $\times 10^{6}$.

The second-order upwind scheme is employed for the spatial discretization of the governing equations. SIMPLE algorithm is applied for coupling pressure and momentum equations. During the computation, the solution is considered to be converged when the non-dimensional residuals of all the variables are less than $10^{-5}$.

\section{CFD Model Validation}

The WT experimental data obtained from the WT database (CODASC, www.codasc.de) for the cases with $W / H=1$ and $L / H=10$ under $\alpha=0^{\circ}, 45^{\circ}$ and $90^{\circ}$ (see Fig. 1) are adopted for the validation of the present CFD model. The wind tunnel has a test section of $2 \mathrm{~m}$ long, $2 \mathrm{~m}$ wide and $1 \mathrm{~m}$ high. In the test section, a boundary layer flow with mean velocity $U(z)$ and turbulent intensity $I_{u}(z)$ in the form of the power law formula were reproduced:

$$
\begin{aligned}
& \frac{U(z)}{U\left(z_{\text {ref }}\right)}=\left(\frac{z}{z_{\text {ref }}}\right)^{0.3} \\
& \frac{I_{u}(z)}{I_{u}\left(z_{\text {ref }}\right)}=\left(\frac{z}{z_{\text {ref }}}\right)^{-0.36}
\end{aligned}
$$

And $U\left(z_{r e f}\right)=4.7 \mathrm{~m} \mathrm{~s}^{-1}\left(z_{r e f}=H=0.12 \mathrm{~m}\right)$ was realized in the WT experiments.

In order to match the corresponding WT experimental conditions in the CFD simulations, the inlet vertical profiles of wind velocity $U(z)$, turbulent kinetic energy $k$ and turbulent dissipation rate $\varepsilon$ are specified as follows (Salim et al., 2011a, b):

$$
\begin{aligned}
& U(z)=4.7\left(\frac{z}{H}\right)^{0.3} \\
& k=\frac{u_{*}^{2}}{\sqrt{C_{u}}}\left(1-\frac{z}{\delta}\right) \\
& \varepsilon=\frac{u_{*}^{3}}{\kappa z}\left(1-\frac{z}{\delta}\right)
\end{aligned}
$$

where $\kappa=0.4$ is the von Karman constant, $u_{*}=0.54 \mathrm{~m} \mathrm{~s}^{-1}$ is the friction velocity, and $\delta=0.5 \mathrm{~m}$ is the boundary layer depth.

In the WT experiments, the $\mathrm{SF}_{6}$ tracer gas were continuously released from the four line sources. Mean concentrations of $\mathrm{SF}_{6}$ were measured on the canyon walls and presented in terms of the dimensionless pollutant concentration $K$ :

$$
K=\frac{C U_{H} H}{Q_{s} / l}
$$


where $C$ is the measured volume fraction of $\mathrm{SF}_{6}$ (pollutant) in the mixture, $U_{H}$ is the flow velocity at building height $H$ in the undisturbed approach flow, $Q_{s}$ is the source strength for $\mathrm{SF}_{6}$ gas and $l$ is the source length.

Fig. 3 shows the profiles of computed and WT measured dimensionless pollutant concentration $K$ on six vertical lines on Wall A (the interior canyon wall on Building A) and on Wall B (the interior canyon wall on Building B) (three lines on each wall: $Y / H=0, Y / H=1.26$ and $Y / H=$ 3.79) under $\alpha=90^{\circ}$. In this figure, the CFD results are in good agreement with the WT measured data on the three lines on Wall $\mathrm{A}$ and on the two lines $(Y / H=0$ and $Y / H=$ 1.26) on Wall B. On Wall B, both the numerical results and WT measurements reveal that the concentration level at $Y / H=3.79$ is much lower than those at $Y / H=0$ and $Y / H=$ 1.26. Fig. 4 presents the distributions of computed and measured concentration $K$ along six vertical lines on Canyon Walls A and B under $\alpha=45^{\circ}$. From Fig. 4, it can be seen clearly that the CFD predictions match well with the WT measured data for all the measurement points on the six lines. Fig. 5 shows the profiles of computed and measured concentration $K$ on three vertical lines on Wall A under $\alpha=0^{\circ}$. Since the airflow and canyon geometry are symmetric with respect to the vertical plane passing through the canyon center axis under $\alpha=0^{\circ}$, the profiles are only presented on one wall. In Fig. 5, the CFD results closely match the WT measurements on all the three lines.

Fig. 6 shows the distributions of computed and WT measured dimensionless concentration $K$ on the canyon walls under $\alpha=90^{\circ}, 45^{\circ}$ and $0^{\circ}$. Fig. 6(a) presents the distributions under $\alpha=90^{\circ}$. Clearly, both the CFD prediction and WT measurement reveal that the concentration levels on Wall A (leeward wall) are much higher than those on Wall B (windward wall) and that the concentration decreases remarkably towards the street ends on both walls. In fact, the concentration distribution features are caused by two vortex structures: a clockwise vortex $(\mathrm{CV})$ created in the middle part of the canyon, and corner eddies induced at the
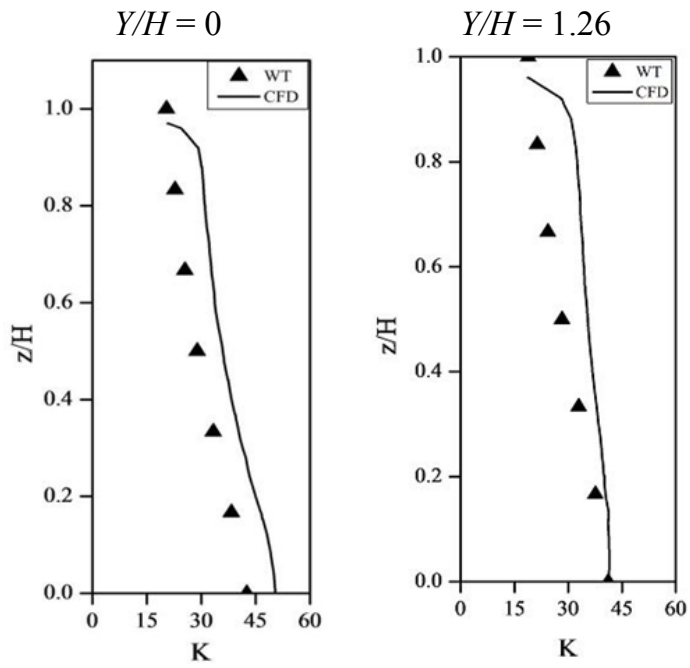

(a) Wall A
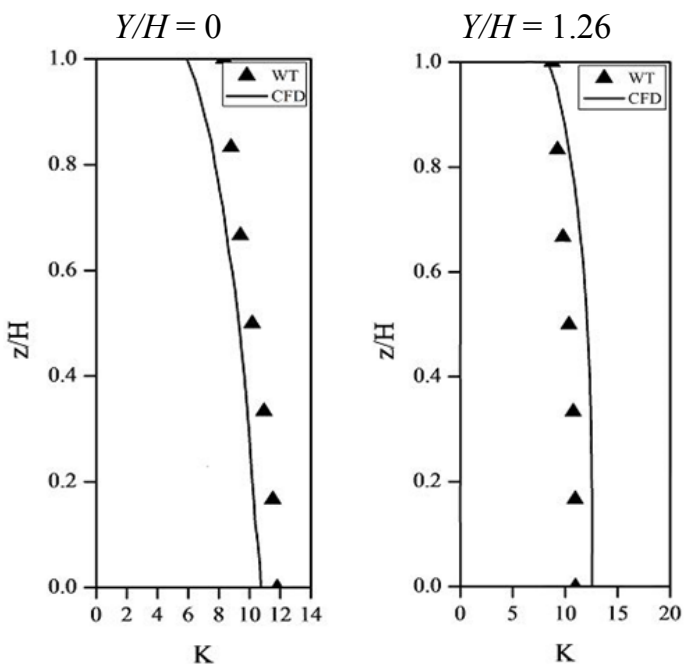

(b) Wall B
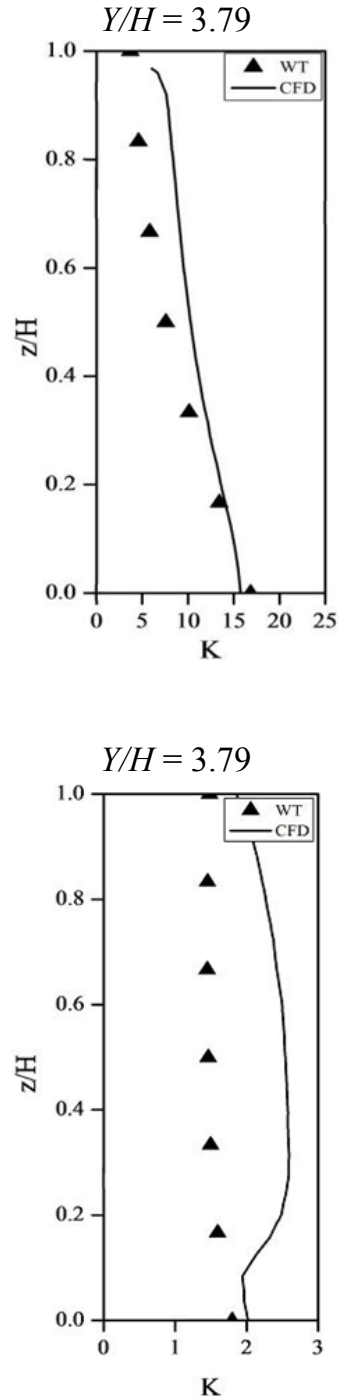

K

Fig. 3. Profiles of dimensionless pollutant concentration $K$ on six vertical lines on Walls A and B of the canyon subjected to a perpendicular wind direction $\left(\alpha=90^{\circ}\right)$. 

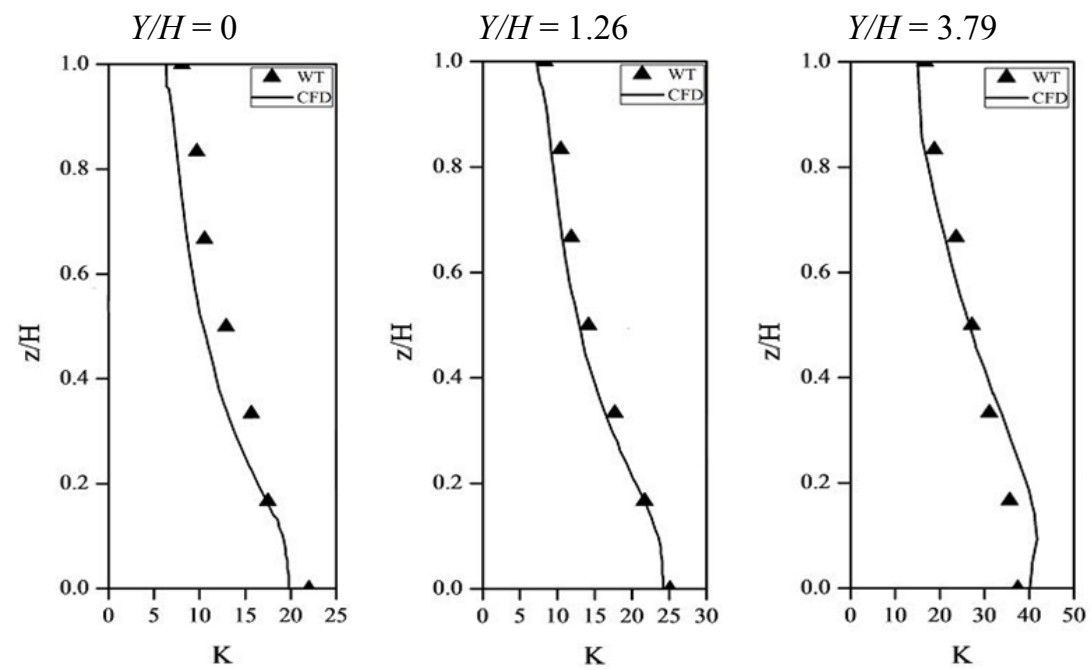

(a) Wall A
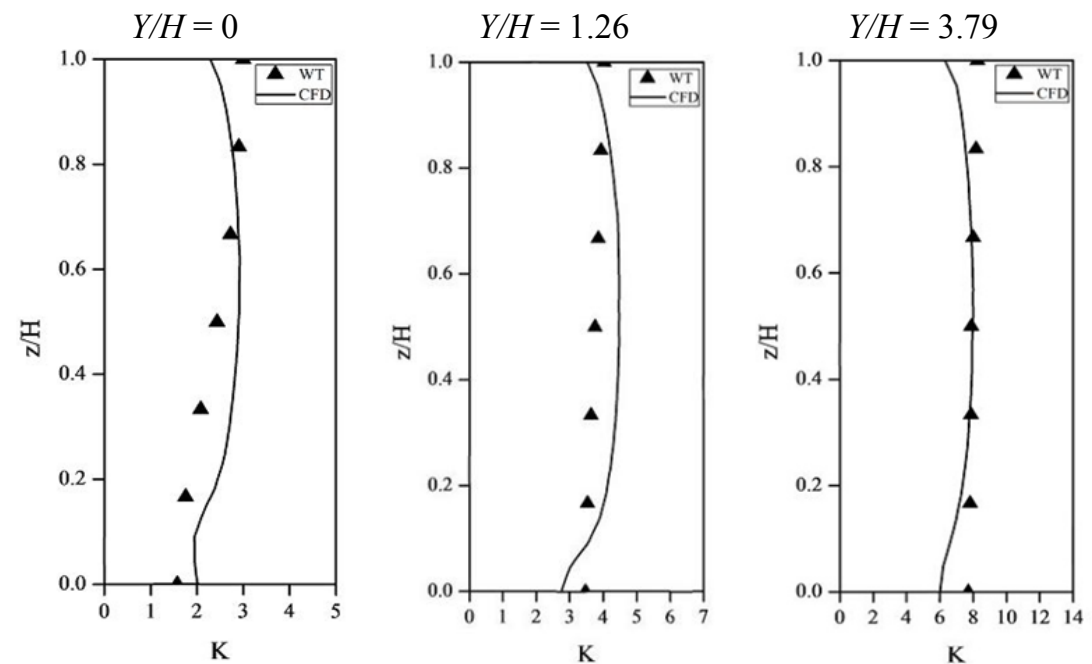

(b) Wall B

Fig. 4. Profiles of dimensionless pollutant concentration $K$ on six vertical lines on Walls A and B of the canyon subjected to an oblique wind direction of $\alpha=45^{\circ}$.
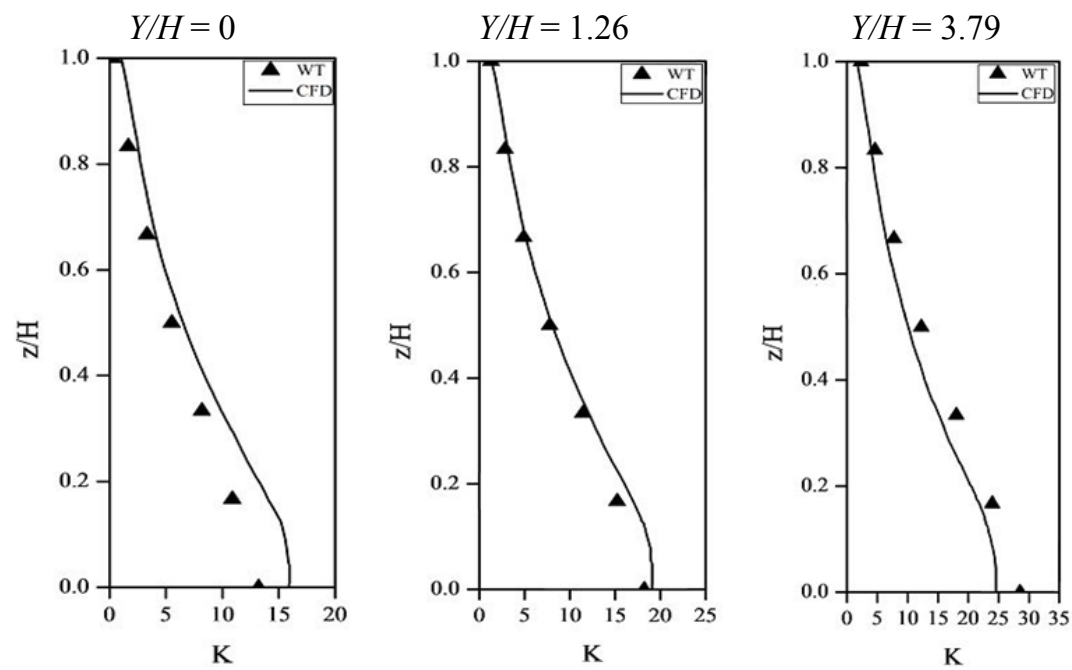

Fig. 5. Profiles of dimensionless pollutant concentration $K$ on three vertical lines on Wall A of the canyon subjected to a parallel wind direction $\left(\alpha=0^{\circ}\right)$. 


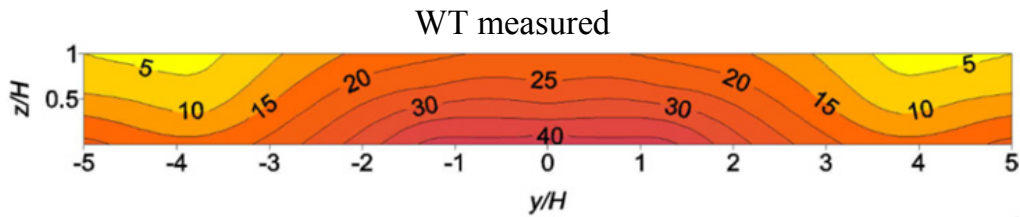

Wall B

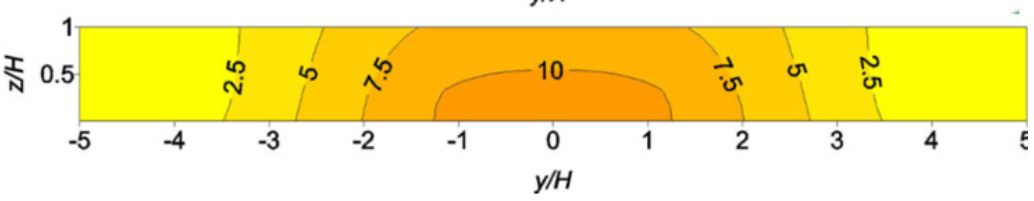

CFD simulate

Wall A

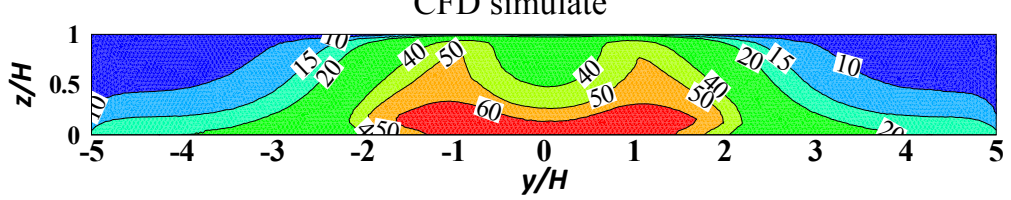

Wall B

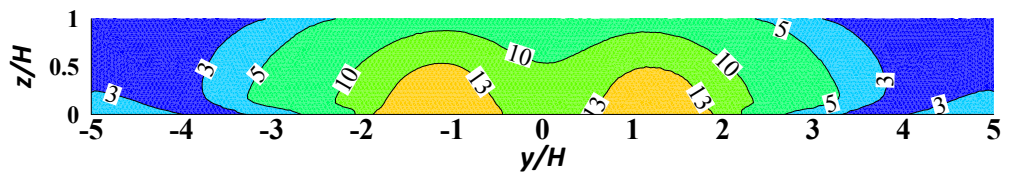

(a) $\alpha=90^{\circ}$

WT measured

Wall A

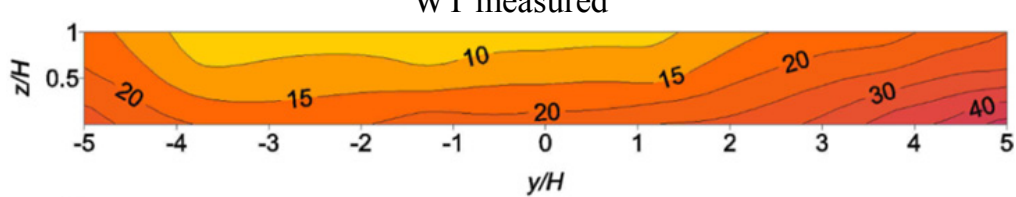

Wall B

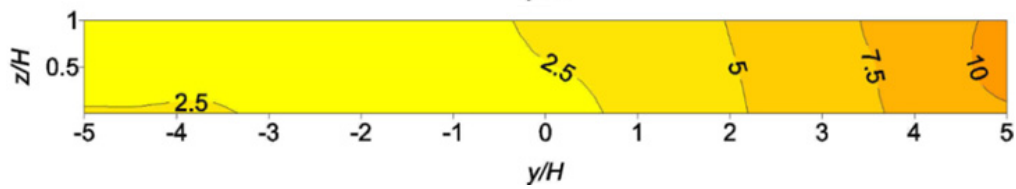

CFD simulate

Wall A

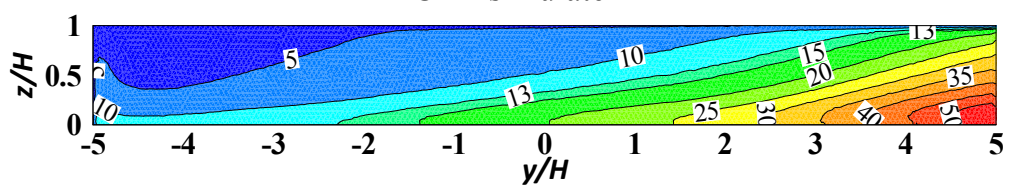

Wall B

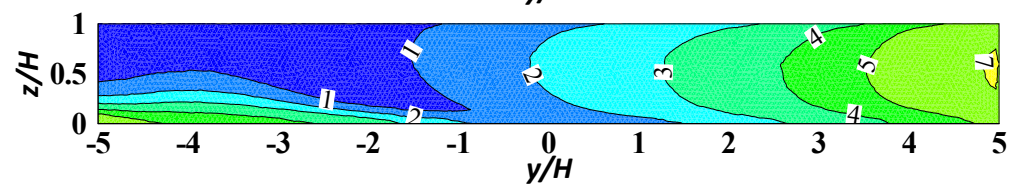

(b) $\alpha=45^{\circ}$

WT measured

Wall A/Wall B

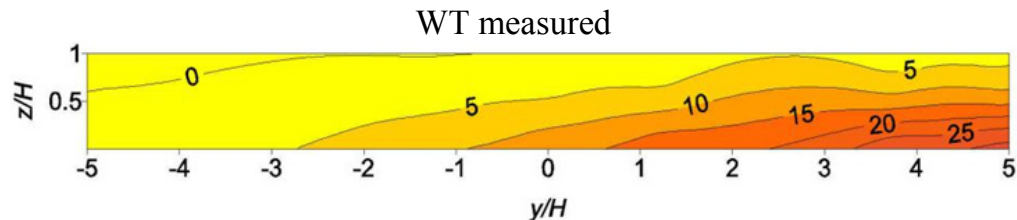

Wall A/Wall B

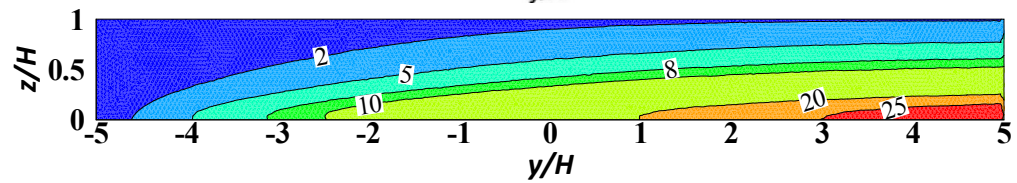

(c) $\alpha=0^{\circ}$

Fig. 6. Dimensionless pollutant concentrations $K$ at the Walls of the canyon with $L / H=10$ under three different wind directions. 
canyon ends (Gromke and Ruck, 2007). Furthermore, it can be observed from Fig. 6(a) that the concentration levels obtained by the CFD model are slightly larger than those obtained by the WT measurement on both walls.

Fig. 6(b) displays the computed and WT measured concentration distributions on the canyon walls under $\alpha=45^{\circ}$. At the upstream part of Wall A (especially, at $Y / H>-2$ ) the CFD-predicted concentrations are obviously lower than those obtained by the WT measurements, whereas at the other part of Wall A (at $Y / H>-2$ ) and at the whole Wall B the computed concentrations are in reasonable agreement with the WT measurements.

Fig. 6(c) shows the computed and WT measured concentration distributions on the canyon walls under $\alpha=0^{\circ}$. Obviously, the concentration on the canyon wall increases significantly from the upstream entry $(Y / H>-5)$ to the downstream edge $(Y / H=5)$. This is because the channel flow conveys the pollutants from the line sources towards the downstream end of the canyon. In Fig. 6(c), the computed concentrations on the canyon walls are in very good agreement with those of the WT measurements.

As demonstrated above, the numerical and WT measured results are in good agreement. Thus, the CFD model applied in this study is reliable for simulating flow and pollutant dispersion inside the canyon under various approaching wind directions.

\section{RESULTS AND DISCUSSION}

The verified CFD model is adopted to perform the numerical simulations. In each simulation case, the boundary conditions and the pollutant source parameters are set the same as those utilized in the above three test cases for the model validation.

\section{Effects of Wind Direction on Air Exchange in the Street Canyon}

The concept of ACH used in street-canyon airflow problems, which represents the volumetric air exchange per unit time, was outlined in several literatures ( $\mathrm{Li}$ et al., 2005; Liu et al., 2005; Cheng et al., 2009; Nazarian and Kleissl, 2016). Positive $\mathrm{ACH}(\mathrm{ACH}+)$ represents the removal of air from the canyon to the outside environment, while the negative $\mathrm{ACH}(\mathrm{ACH}-)$ represents the entry of air from the outside into the canyon. The magnitudes of $\mathrm{ACH}+$ and $\mathrm{ACH}-$ are equal due to the mass conservation in an incompressible flow. For the 3D street canyon used in this study, the ACH can be evaluated by the sum of ACHs along the top and two sides of the canyon as:

$$
\begin{aligned}
& \mathrm{ACH}+=\left(\mathrm{ACH}_{\mathrm{Top}^{+}}+\right)+\left(\mathrm{ACH}_{\mathrm{Side}}+\right)+\left(\mathrm{ACH}_{\mathrm{Side} 2}+\right) \\
& \mathrm{ACH}-=\left(\mathrm{ACH}_{\mathrm{Top}}-\right)+\left(\mathrm{ACH}_{\mathrm{Side}^{1}}-\right)+\left(\mathrm{ACH}_{\mathrm{Side}^{2}}\right)
\end{aligned}
$$

where $\mathrm{ACH}_{\text {Top }}$ is the $\mathrm{ACH}$ along the top surface of the canyon, $\mathrm{ACH}_{\text {Sidel }}$ is the $\mathrm{ACH}$ along Side 1 (the vertical interface between canyon and ambient flow at $Y / H=-5$ ), and $\mathrm{ACH}_{\text {Side2 }}$ is the $\mathrm{ACH}$ along Side 2 (the vertical interface between canyon and ambient flow at $Y / H=5$ ).
The $\mathrm{ACH}$ along a surface is made up of the mean $(\overline{\mathrm{ACH}})$ and turbulence $\left(\mathrm{ACH}^{\prime}\right)$ components:

$\mathrm{ACH}=\overline{\mathrm{ACH}}+\mathrm{ACH}^{\prime}$

where $\overline{\mathrm{ACH}}$ is induced by the mean velocity.

$\mathrm{ACH}^{\prime}$ is induced by the normal velocity fluctuation. The approach proposed by $\mathrm{Li}$ et al. (2005) is adopted to calculate the $\mathrm{ACH}^{\prime}$. They assumed that the air exchange due to turbulence is divided evenly into entering and leaving parts. Also, they assumed the isotropic turbulence because of a high Reynolds number flow. Thus, the $\mathrm{ACH}^{\prime}$ along the top of the canyon can be determined by the turbulent kinetic energy $k$ as follows:

$$
\mathrm{ACH}_{\mathrm{Top}}^{\prime}+=-\mathrm{ACH}_{\mathrm{Top}}^{\prime}-=\frac{1}{\sqrt{6}} \int_{\Gamma_{3}} \sqrt{k} d \Gamma_{3}
$$

where $\Gamma_{3}=L \times W$ is the area of top surface of the canyon.

Based on the approach proposed by Li et al. (2005), the $\mathrm{ACH}^{\prime}$ along the two sides of the canyon can be evaluated as:

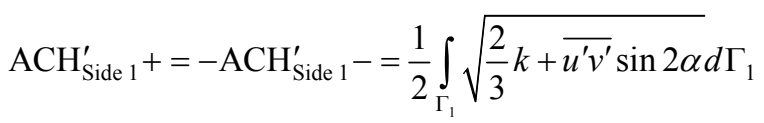

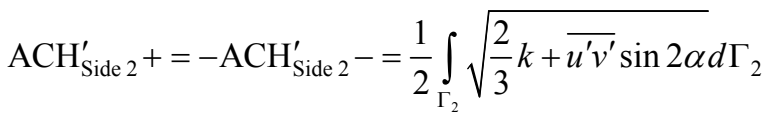

where $\Gamma_{1}=H \times W$ is the area of Side 1 , and $\Gamma_{2}=H \times W$ is that of Side 2. $u^{\prime}$ and $v^{\prime}$ are the fluctuating velocity components in the $x$ - and $y$-directions, respectively. The Reynolds stress is modeled by the eddy-viscosity model, such that:

$-\overline{u^{\prime} v^{\prime}}=v_{t}\left(\frac{\partial u}{\partial y}+\frac{\partial v}{\partial x}\right)$

Substituting Eq. (20) into Eqs. (18) and (19) leads to the following expressions of $\mathrm{ACH}^{\prime}$ along the two sides of the canyon:

$$
\begin{aligned}
\mathrm{ACH}_{\text {Side } 1}^{\prime}+ & =-\mathrm{ACH}_{\text {Side } 1}^{\prime}- \\
& =\frac{1}{2} \int_{\Gamma_{1}} \sqrt{\frac{2}{3} k-v_{t}\left(\frac{\partial u}{\partial y}+\frac{\partial v}{\partial x}\right) \sin 2 \alpha d \Gamma_{1}} \\
\mathrm{ACH}_{\text {Side } 2}^{\prime}+ & =-\mathrm{ACH}_{\text {Side } 2}^{\prime}- \\
& =\frac{1}{2} \int_{\Gamma_{2}} \sqrt{\frac{2}{3} k-v_{t}\left(\frac{\partial u}{\partial y}+\frac{\partial v}{\partial x}\right) \sin 2 \alpha d \Gamma_{2}}
\end{aligned}
$$

The $\mathrm{ACH}$ values can be non-dimensionalized by the canyon volume $V(=L \times W \times H)$ and the reference time scale $T\left(=H / U_{H}\right)$. Tables 1 and 2 illustrate the positive and 

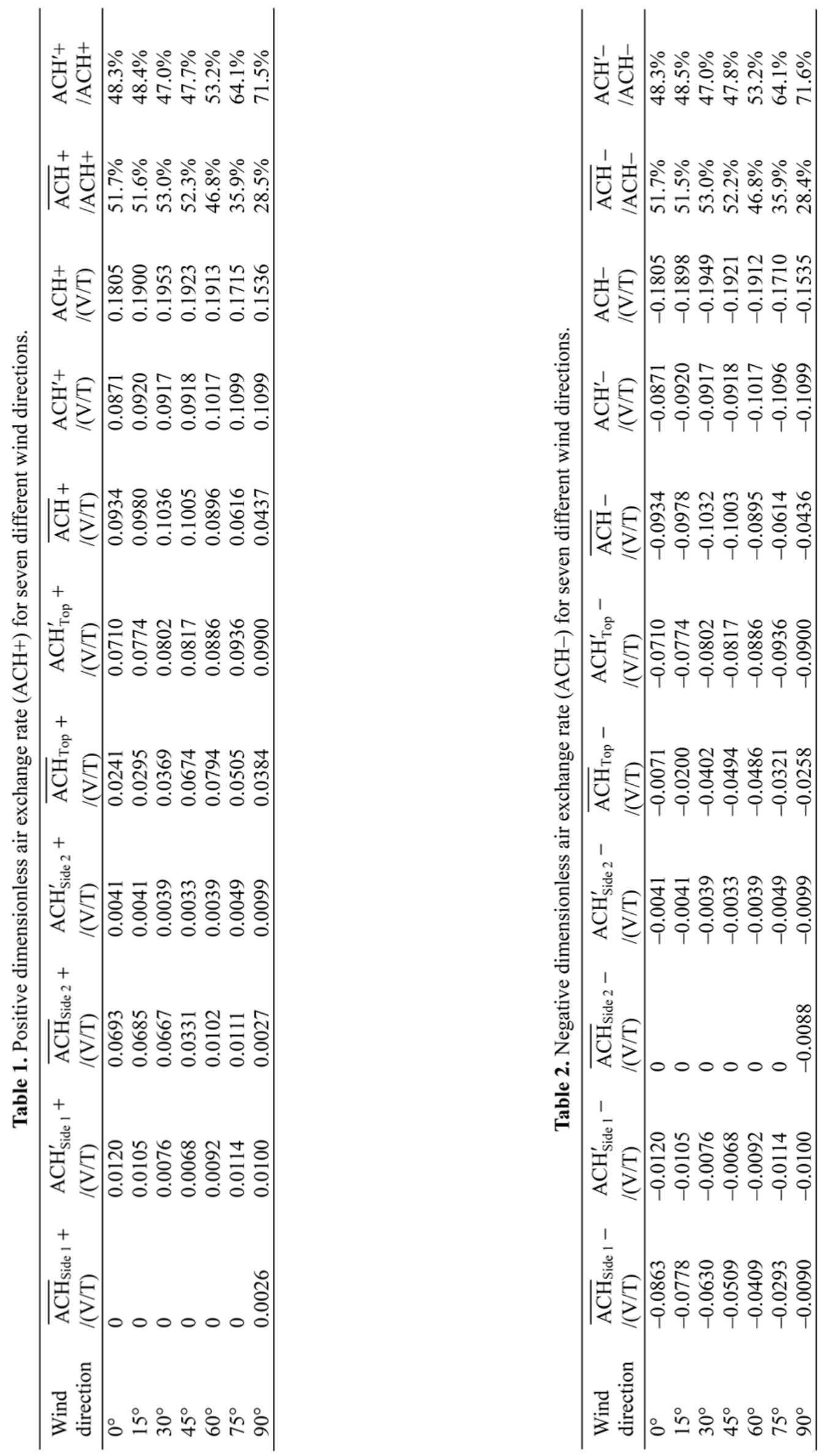
negative dimensionless $\mathrm{ACH}$ for the seven different wind directions, respectively. From these tables, it is clear that the difference between the magnitude of $\mathrm{ACH}+$ and that of $\mathrm{ACH}-$ is very small (the normalized difference $\varphi$ $(=|(\mathrm{ACH}+)-| \mathrm{ACH}-|| / \mathrm{ACH}+)$ is between 0.00 and $0.29 \%$ among the seven cases), indicating that the calculation turns out to be very accurate (i.e., the mass conservation is satisfied strictly in the simulation).

As shown in Table $1, \overline{\mathrm{ACH}}+$ is close to $\mathrm{ACH}^{\prime}+$ for $\alpha=0^{\circ}, 15^{\circ}, 30^{\circ}, 45^{\circ}$ and $60^{\circ}$. However, for $\alpha=75^{\circ}$ and $90^{\circ} \mathrm{ACH}^{\prime}+$ is markedly greater than $\overline{\mathrm{ACH}}+$ (especially for $\alpha=90^{\circ}, \mathrm{ACH}^{\prime}+$ accounts for $71.5 \%$ of $\mathrm{ACH}+$ ), demonstrating the importance of turbulence to the canyon ventilation. The magnitudes of $\mathrm{ACH}+$ are close among the cases with $\alpha=15^{\circ}, 30^{\circ}, 45^{\circ}$ and $60^{\circ}$. ACH+ reaches maximum at $\alpha=30^{\circ}$ and minimum at $\alpha=90^{\circ}(\mathrm{ACH}+$ at $\alpha=90^{\circ}$ is $78.6 \%$ of that at $\alpha=30^{\circ}$ ).

As illustrated in Table 2, $\overline{\mathrm{ACH}}-$ is close to $\mathrm{ACH}^{\prime}-$ for $\alpha=0^{\circ}, 15^{\circ}, 30^{\circ}, 45^{\circ}$ and $60^{\circ}$. For $\alpha=75^{\circ}$ and $90^{\circ}$ (especially, for $\alpha=90^{\circ}$ ) the magnitude of $\mathrm{ACH}^{\prime}-$ is markedly greater than that of $\overline{\mathrm{ACH}}-$. The magnitudes of $\mathrm{ACH}-$ are close among the cases with $\alpha=15^{\circ}, 30^{\circ}, 45^{\circ}$ and $60^{\circ}$. The strongest entry of air occurs at $\alpha=30^{\circ}$ while the weakest occurs at $\alpha=90^{\circ}$.

From Table 1, it can be obtained that the ratio of positive $\mathrm{ACH}$ through the two sides to the positive ACH through the canyon is 0.473 for $\alpha=0^{\circ}, 0.453$ for $\alpha=15^{\circ}, 0.400$ for $\alpha=30^{\circ}, 0.255$ for $\alpha=45^{\circ}, 0.122$ for $\alpha=60^{\circ}, 0.160$ for $\alpha=$ $75^{\circ}$ and 0.164 for $\alpha=90^{\circ}$. Meanwhile, it can be obtained from Table 2 that the ratio of negative $\mathrm{ACH}$ through the two sides to the negative $\mathrm{ACH}$ through the canyon is 0.567 for $\alpha=0^{\circ}, 0.487$ for $\alpha=15^{\circ}, 0.382$ for $\alpha=30^{\circ}, 0.318$ for $\alpha=45^{\circ}, 0.282$ for $\alpha=60^{\circ}, 0.265$ for $\alpha=75^{\circ}$ and 0.246 for $\alpha=90^{\circ}$. Clearly, for a 3D long canyon scenario in the current study, the removal and entry of air across the two sides of the canyon also play an important role in canyon ventilation for all the seven wind directions examined (especially, for $\alpha=0^{\circ}, 15^{\circ}, 30^{\circ}$ and $45^{\circ}$ ).

It should be noted that Tables 1 and 2 show the $\mathrm{ACH}$ for a reduced-scale isolated canyon model. For scaling to the real world from the results in these two tables, the dimensionless air exchange rate can be considered invariant to scale ( $R e$ sensitivity effects can be ignored). Thus, the $\mathrm{ACH} / \mathrm{V}\left(\mathrm{h}^{-1}\right)$ for the real canyon can be evaluated $\left(\mathrm{ACH} / \mathrm{V}\left(\mathrm{h}^{-1}\right)\right.$ is 169.9 for $\alpha=0^{\circ}, 178.6$ for $\alpha=15^{\circ}, 183.6$ for $\alpha=30^{\circ}, 180.8$ for $\alpha=45^{\circ}, 179.8$ for $\alpha=60^{\circ}, 161.2$ for $\alpha=75^{\circ}$ and 144.4 for $\left.\alpha=90^{\circ}\right)$.

\section{Characteristics of Airflow inside the Canyon under Various Wind Directions}

Fig. 7 shows the velocity vectors and dimensionless pollutant concentration contours at the human respiration height $(\mathrm{z}=0.01 \mathrm{~m}$, i.e., $1.5 \mathrm{~m}$ in the full scale) under the seven wind directions. From Fig. 7(a), it is clear that flow channeling is produced inside the canyon for the parallel wind. For each of the five oblique winds, a horizontal flow along the canyon axis, combined with a small recirculation next to the upstream end of Wall A, is formed (Figs. 7(b)7(f)). For each of the oblique winds with $\alpha=15^{\circ}, 30^{\circ}$ and $45^{\circ}$, a strong horizontal flow along the canyon axis passes through the whole canyon length. Meanwhile, for each of the oblique winds with $\alpha=60^{\circ}$ and $75^{\circ}$, a strong horizontal flow along the canyon axis is only developed in the upstream part (at $Y<0$ ) of the canyon (Figs. 7(e) and 7(f)). For the perpendicular wind, the airflow coming through the two sides into the canyon is observed distinctly (Fig. 7(g)). This flow phenomenon is caused by the corner eddies developed at the canyon ends. Moreover, Fig. 7(g) shows that the weak velocity vectors in the inner area of the canyon point nearly orthogonal to the leeward wall, due to the formation of a strong CV.

Figs. 8-13 show the velocity vectors and dimensionless concentration contours on the five vertical cross sections of the canyon under the wind directions with $\alpha=15^{\circ}, 30^{\circ}$, $45^{\circ}, 60^{\circ}, 75^{\circ}$ and $90^{\circ}$. For $\alpha=15^{\circ}$, the in-canyon flow pattern is mainly governed by a street-axis parallel flow and consequently the velocity components are very weak on each of the five vertical cross sections (Fig. 8). On the section with $Y / H=-3.79$ the velocity vectors in one part point towards Building $\mathrm{A}$ while those in the other part point towards Building B (Fig. 8(a)). On the section with $Y / H=-1.26$, most of the velocity vectors point towards Building A and only the velocity vectors near the top of the canyon point towards Building B (Fig. 8(b)). Meanwhile, on each of the sections with $Y / H=0,1.26$ and 3.79 a very weak CV is developed (Figs. 8(c)-8(e)). For $\alpha=30^{\circ}$, a CV is formed on each of the sections with $Y / H=-1.26,0,1.26$ and 3.79 (Figs. 9(b)-9(e)). Meanwhile, on the section with $Y / H=-3.79$, a small CV next to the upper part of Wall $\mathrm{A}$ is generated with almost zero velocity components orthogonal to the street-axis in a region close to Wall B (Fig. 9(a)). For $\alpha=45^{\circ}$, a large $\mathrm{CV}$ is developed on each of the sections with $Y / H=-1.26,0,1.26$ and 3.79 and a large distorted $\mathrm{CV}$ with its center being located next to the upper part of Wall $\mathrm{A}$ is established on the section with $Y / H=-3.79$ (Fig. 10). From Figs. 8-10, it can be further obtained that the streetaxis perpendicular flow is strengthened with the increase of $\alpha$ ranging from $0^{\circ}$ to $45^{\circ}$. On each of the five vertical cross sections the vortex flow pattern under $\alpha=60^{\circ}$ (Fig. 11) is very similar to that under $\alpha=45^{\circ}$. For $\alpha=75^{\circ}$ and $90^{\circ}$, a large $\mathrm{CV}$ is developed on each of the five cross sections (Figs. 12 and 13).

Combining Fig. 7(c) with Fig. 9 and Fig. 7(d) with Fig. 10, it can be revealed that the superposition of the horizontal flow along the street axis and the CV results in a corkscrew flow inside the canyon for the oblique winds with $\alpha=30^{\circ}$ and $45^{\circ}$. Combining Fig. 7(e) with Fig. 11 and Fig. 7(f) with Fig. 12, for the oblique winds with $\alpha=60^{\circ}$ and $75^{\circ}$, it can be revealed that an obvious corkscrew flow develops only in the upstream part of the canyon (in the downstream part the flow is governed mainly by a CV). For the perpendicular wind, it can be revealed from Fig. 7(g) and Fig. 13 that a helical flow structure is established in each sideward canyon area due to the superposition of the $\mathrm{CV}$ and the corner eddy, while in the inner area of the canyon the flow pattern is characterized by a large $\mathrm{CV}$ flow driven by the imposed ambient flow above the canyon. 

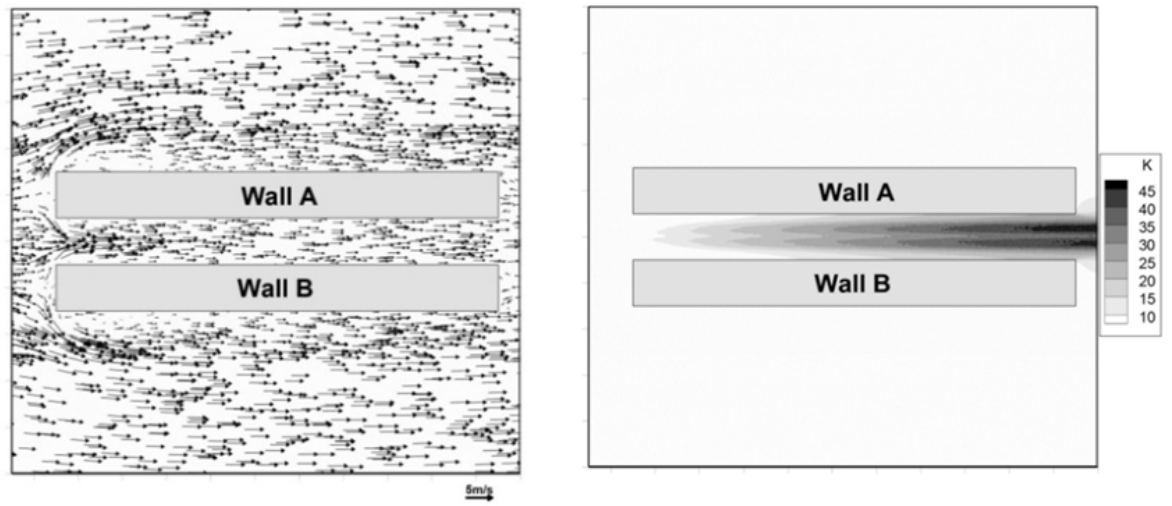

(a) $\alpha=0^{\circ}$
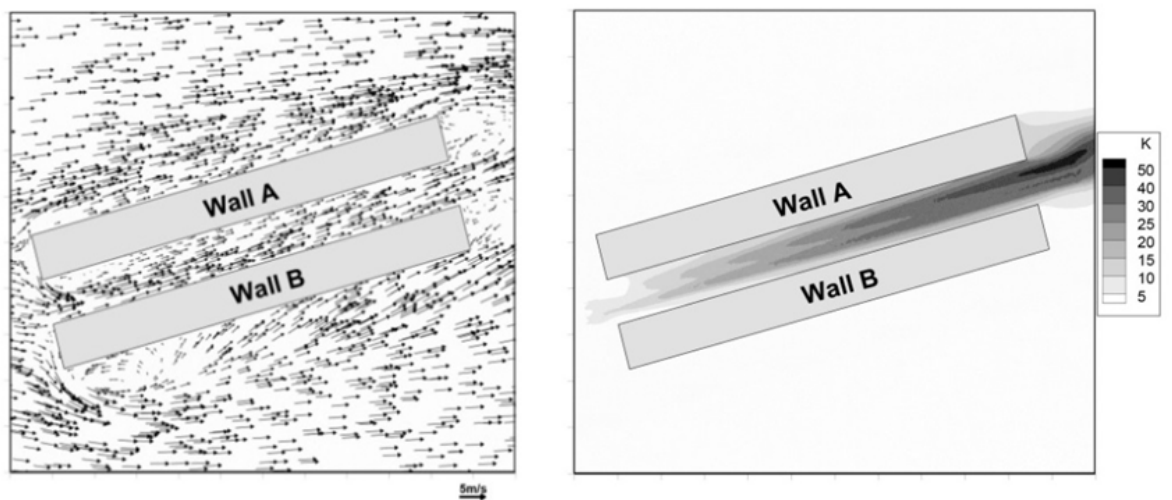

(b) $\alpha=15^{\circ}$
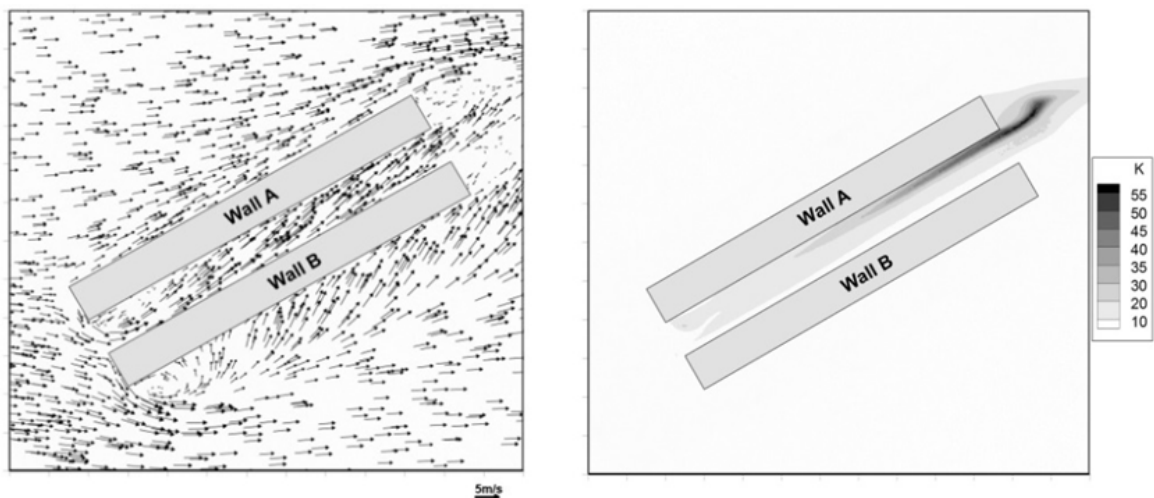

(c) $\alpha=30^{\circ}$
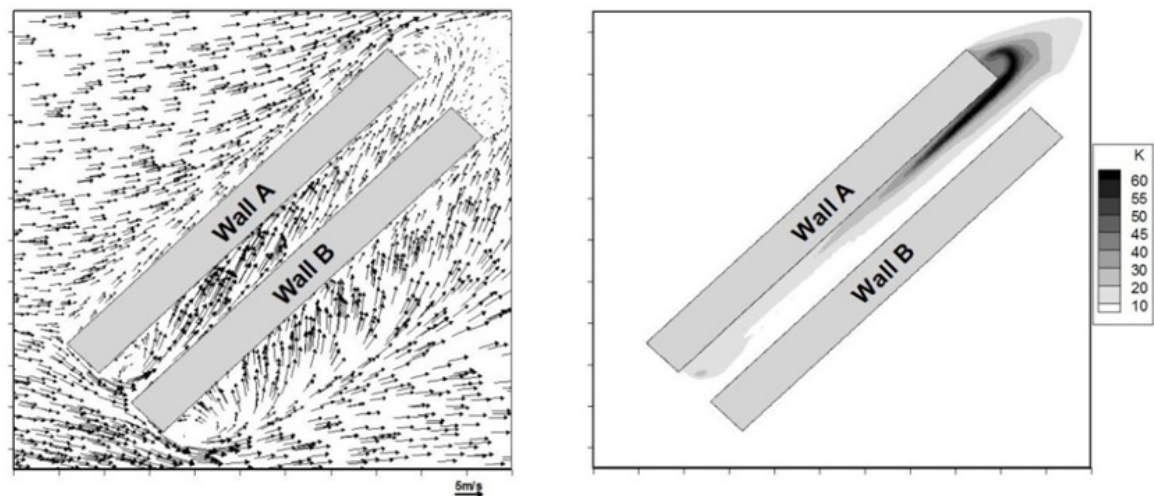

(d) $\alpha=15^{\circ}$

Fig. 7. Velocity vectors and dimensionless pollutant concentrations at the human respiration height $(z=0.01 \mathrm{~m})$ under seven different wind directions. 

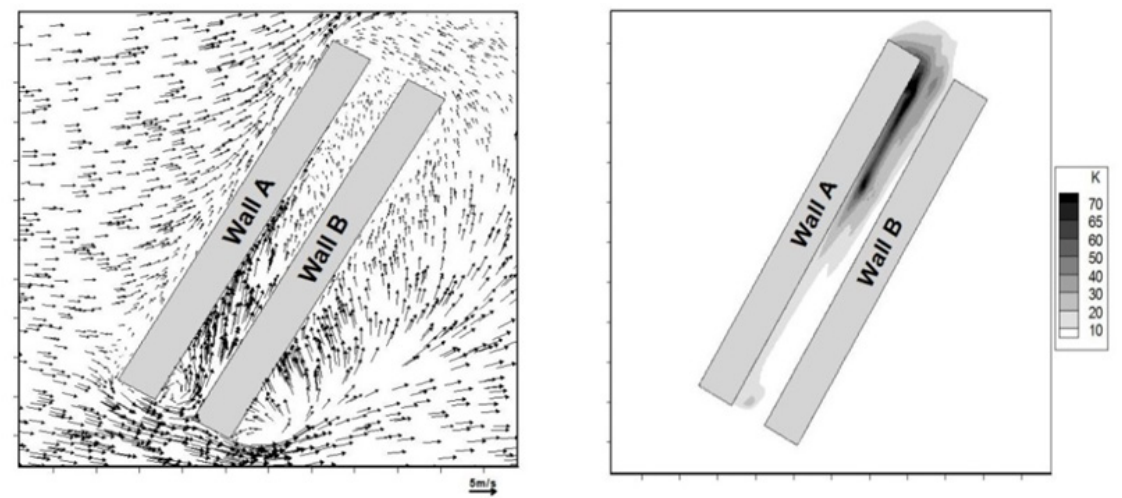

(e) $\alpha=60^{\circ}$
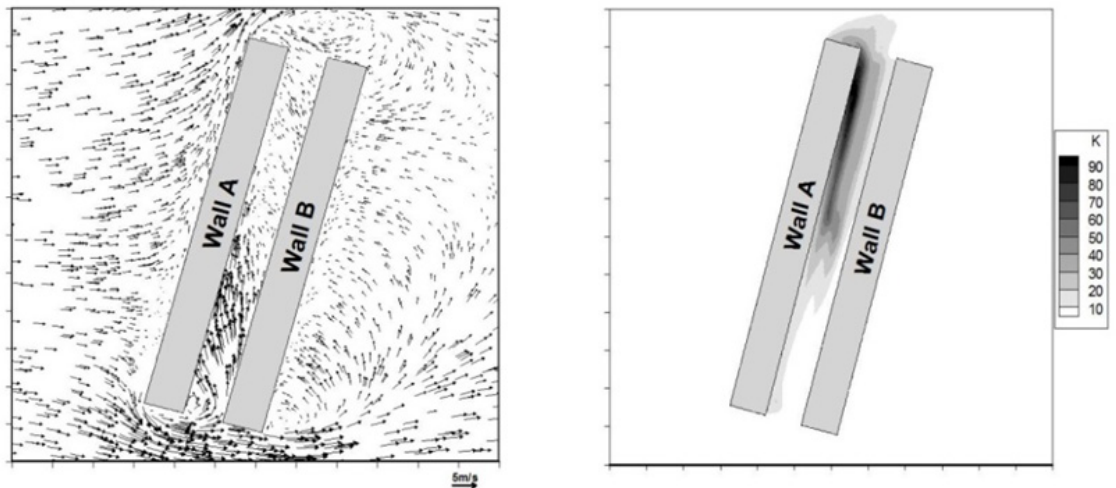

(f) $\alpha=75^{\circ}$
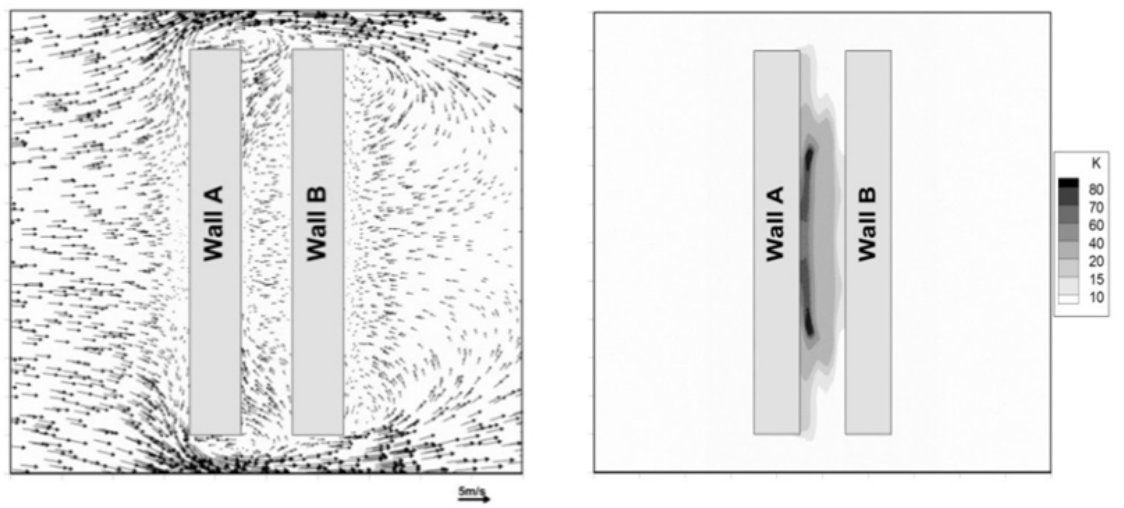

(g) $\alpha=90^{\circ}$

Fig. 7. (continued).

\section{Pollutant Dispersion and Concentrations}

Pollutant Distribution at the Human Respiration Height inside the Canyon

From a health point of view, we should pay much attention to the pollution levels at the human respiration height inside the canyon. For each of the cases with $\alpha=0^{\circ}$ and $15^{\circ}$, the concentration at $\mathrm{z}=0.01 \mathrm{~m}$ increases significantly towards the downstream end of the canyon (Figs. 7(a) and 7(b)) since the pollutants are transported along the street by the strong street-axis parallel flow. For each of the cases with $\alpha=30^{\circ}$ and $45^{\circ}$, the pollutants are transported by the corkscrew flow. As a result, the concentrations at $\mathrm{z}=0.01 \mathrm{~m}$ increase towards the canyon end at $Y / H=5$, with the maximum concentration levels at the Wall A side (Figs. 7(c) and 7(d)).
For each of the cases with $\alpha=60^{\circ}$ and $75^{\circ}$, at $\mathrm{z}=0.01 \mathrm{~m}$ the pollutants are accumulated on the Wall A side in the downstream part of the canyon (Figs. 7(e) and 7(f)) due to the combined effects of the strong corkscrew flow in the upstream part of the canyon and the $\mathrm{CV}$ flow in the downstream part. For $\alpha=90^{\circ}$, at $\mathrm{z}=0.01 \mathrm{~m}$, the pollutants are accumulated on the leeward side, and the pollution levels at the sideward canyon regions are much smaller, due to the enhanced ventilation by laterally entrained air, than those in the inner area of the canyon (Fig. 7(g)).

At $\mathrm{z}=0.01 \mathrm{~m}$, the dimensionless concentration profiles along the line $0.01 \mathrm{~m}$ ( $1.5 \mathrm{~m}$ in reality) away from Wall $\mathrm{A}$ (i.e., the line in the footpath next to Wall A) and along the line $0.01 \mathrm{~m}$ away from Wall B (i.e., the line in the footpath 

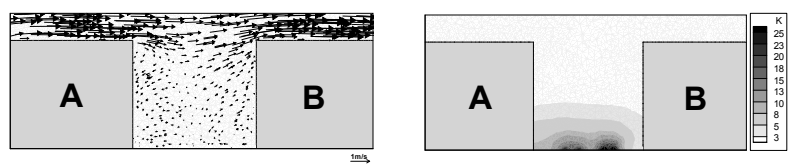

(a) $\vec{Y} / H=-3.79$
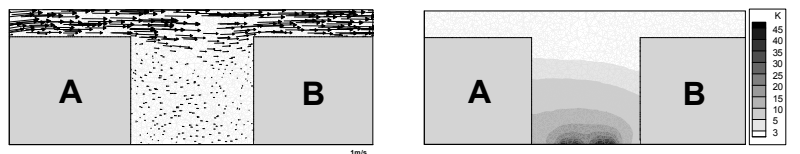

(b) $Y / H=-1.26$
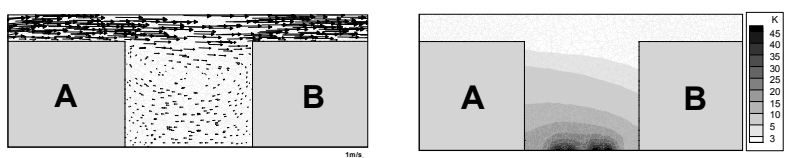

(c) $Y / H=0$
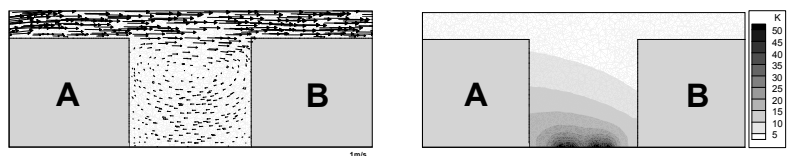

(d) $\stackrel{\mathrm{m}}{Y} / H=1.26$
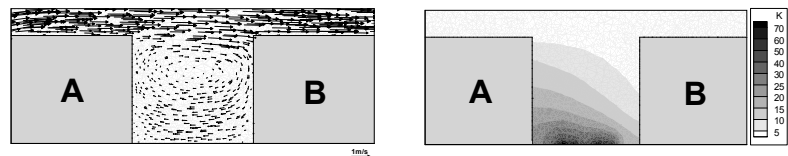

(e) $\vec{Y} / H=3.79$

Fig. 8. Velocity vectors and dimensionless pollutant concentrations on the different vertical cross sections of the canyon under the wind direction of $\alpha=15^{\circ}$.
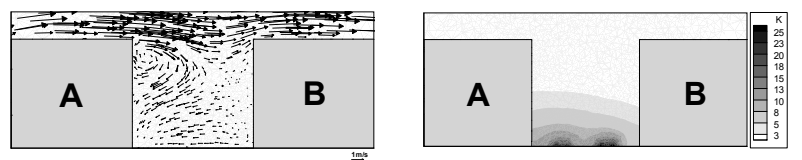

(a) $\bar{Y} / H=-3.79$
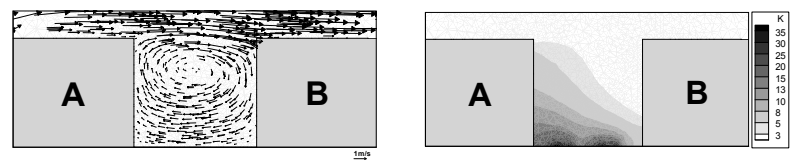

(b) $Y / H=-1.26$
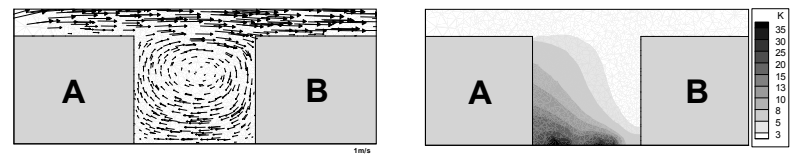

(c) $Y / H=0$
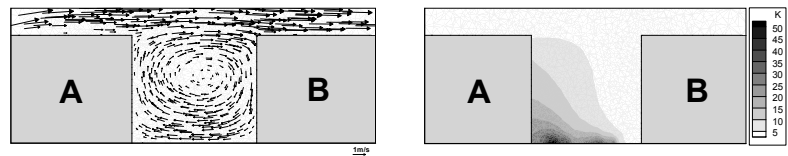

(d) $Y / H=1.26$
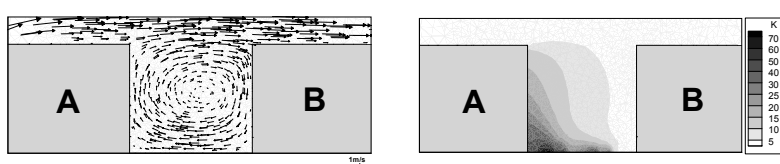

(e) $\vec{Y} / H=3.79$

Fig. 9. Velocity vectors and dimensionless pollutant concentrations on the different vertical cross sections of the canyon under the wind direction of $\alpha=30^{\circ}$. 

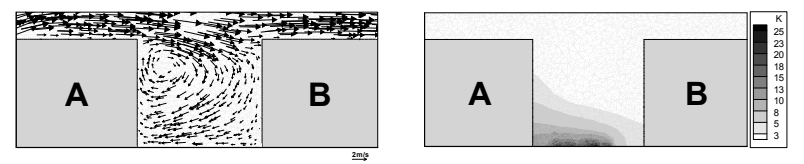

(a) $Y / H=-3.79$
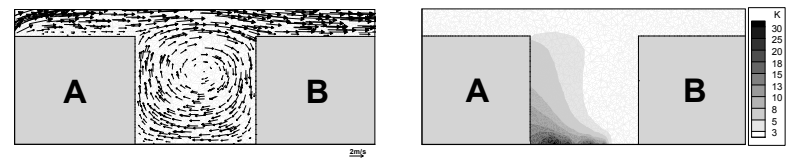

(b) $Y / H=-1.26$
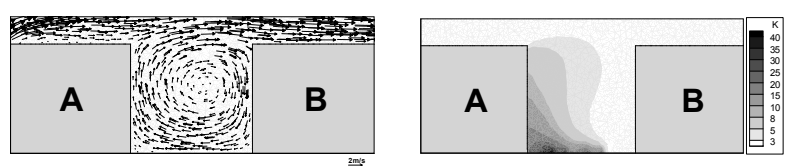

(c) $Y / H=0$
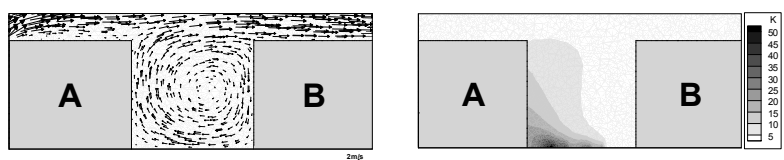

(d) $\mathrm{Y} / H=1.26$
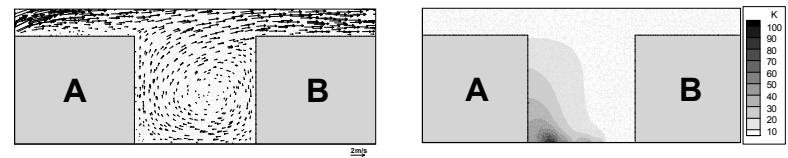

(e) $Y / H=3.79$

Fig. 10. Velocity vectors and dimensionless pollutant concentrations on the different vertical cross sections of the canyon under the wind direction of $\alpha=45^{\circ}$.
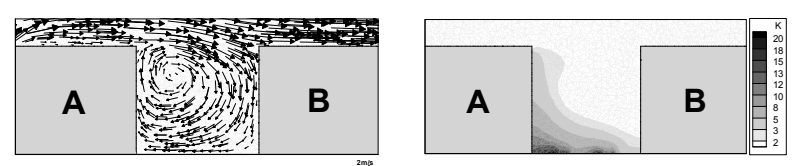

(a) $Y / H=-3.79$
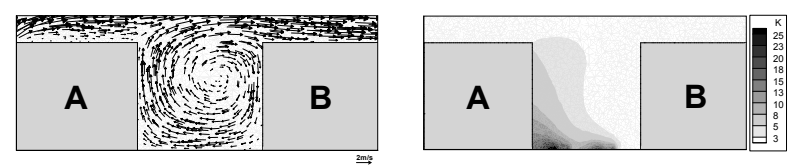

(b) $Y / H=-1.26$
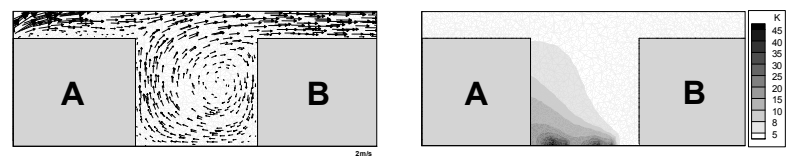

(c) $Y / H=0$
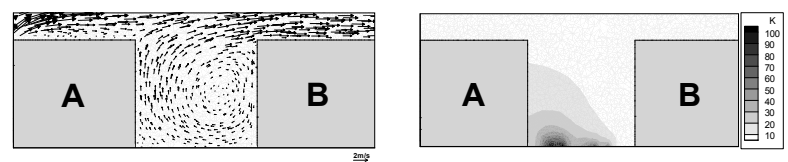

(d) $\vec{Y} / H=1.26$
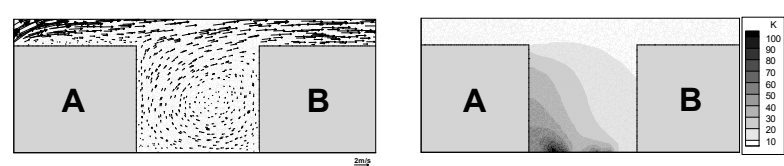

(e) $\stackrel{Y}{Y} / H=3.79$

Fig. 11. Velocity vectors and dimensionless pollutant concentrations on the different vertical cross sections of the canyon under the wind direction of $\alpha=60^{\circ}$. 

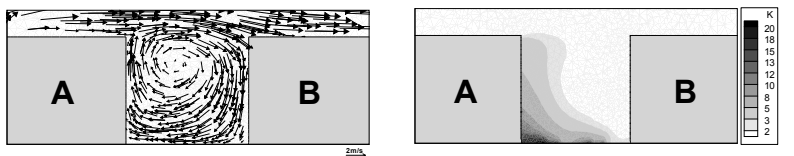

(a) $Y / H=-3.79$
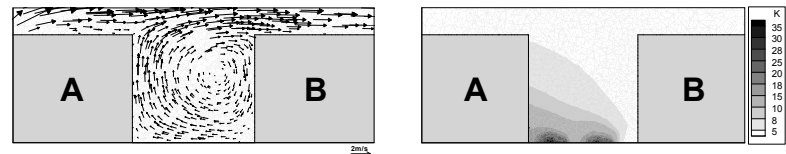

(b) $Y / H=-1.26$
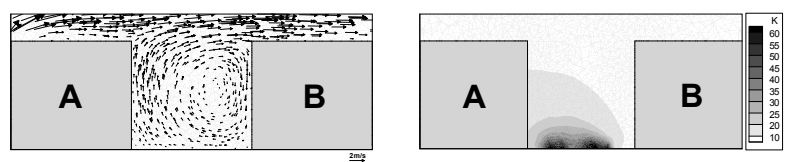

(c) $Y / H=0$
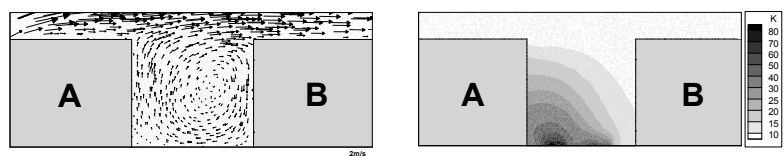

(d) $\mathrm{Y} / H=1.26$
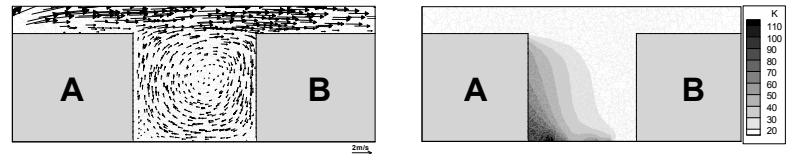

(e) $Y / H=3.79$

Fig. 12. Velocity vectors and dimensionless pollutant concentrations on the different vertical cross sections of the canyon under the wind direction of $\alpha=75^{\circ}$.
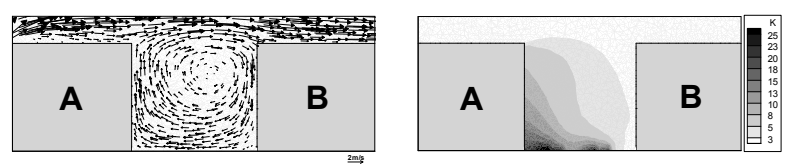

(a) $\vec{Y} / H=-3.79$

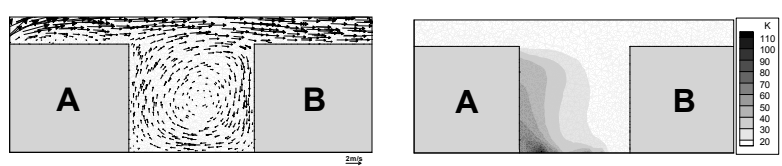

(b) $Y / H=-1.26$

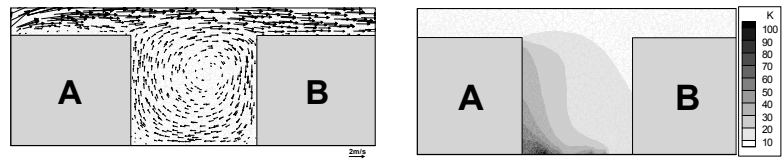

(c) $Y / H=0$
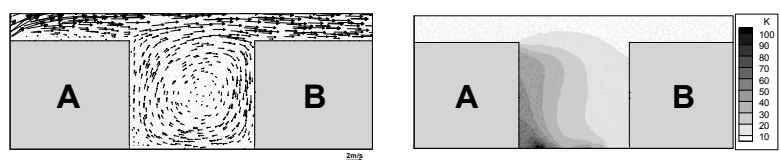

(d) $Y / H=1.26$
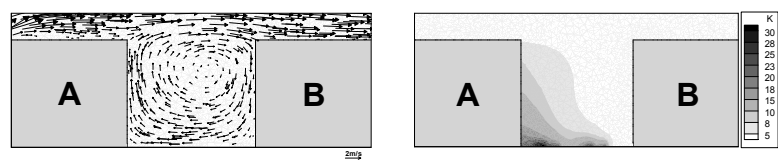

(e) $\vec{Y} / H=3.79$

Fig. 13. Velocity vectors and dimensionless pollutant concentrations on the different vertical cross sections of the canyon under the wind direction of $\alpha=90^{\circ}$. 
next to Wall B) are presented in Fig. 14 for the seven different wind directions. Here, we first analyze the pollutant distributions on the line in the footpath next to Wall A (see Fig. 14(a)). For each of the cases with $\alpha=0^{\circ}$ and $15^{\circ}$, the concentration increases almost linearly from the upstream entry to the downstream end. For each of the cases with $\alpha=30^{\circ}$ and $45^{\circ}$, the concentration also increases with the distance from the upstream entry. The pollutant concentrations under $\alpha=30^{\circ}$ and $45^{\circ}$ are larger significantly (especially at $Y / H>0$ ) than those under $\alpha=0^{\circ}$ and $15^{\circ}$, since under $\alpha=30^{\circ}$ and $45^{\circ}$ the pollutants are conveyed by the CV towards the Wall A side. For each of the cases with $\alpha=60^{\circ}$ and $75^{\circ}$, the pollutants are accumulated along the canyon axis with a peak concentration value near the downstream end (the peak concentration occurs roughly at $Y / H=4.0$ for $\alpha=60^{\circ}$ and at $Y / H=3.5$ for $\left.\alpha=75^{\circ}\right)$. At the downstream part (i.e., at $Y / H>0$ ) of the canyon, the corkscrew flow under $\alpha=60^{\circ}$ and $75^{\circ}$ is very weak and thus the concentrations under these two wind directions are much larger than those under $\alpha=30^{\circ}$ and $45^{\circ}$. For the case with $\alpha=90^{\circ}$, the concentration increases from the canyon ends towards the street center due to the combined actions of the helical flow in the sideward areas of the canyon and the $\mathrm{CV}$ flow in the inner part of the canyon. At $Y / H<2$ the concentration level under $\alpha=90^{\circ}$ is greater (or even much greater) than those under the other six wind directions while at $Y / H>3$ the pollution level under $\alpha=90^{\circ}$ is smaller than those under $\alpha=0^{\circ}$ and $15^{\circ}$ and much smaller than those under $\alpha=30^{\circ}, 45^{\circ}, 60^{\circ}$ and $75^{\circ}$. Moreover, from Fig. 14(a), it can be obtained that at $Y / H>2$ the pollution level increases greatly with $\alpha$ ranging from $45^{\circ}$ to $75^{\circ}$. Furthermore, from Fig. 14(a) the highest concentration is found at $\alpha=75^{\circ}$, not at $\alpha=90^{\circ}$. Comparing Fig. 14(a) with Fig. 14(b), it is clear that the pollution level in the footpath next to Wall $\mathrm{A}$ is much higher than that in the footpath next to Wall B for the oblique and perpendicular winds examined. From Fig. 14(b), in the footpath next to Wall B the highest concentration is found at $\alpha=0^{\circ}$.

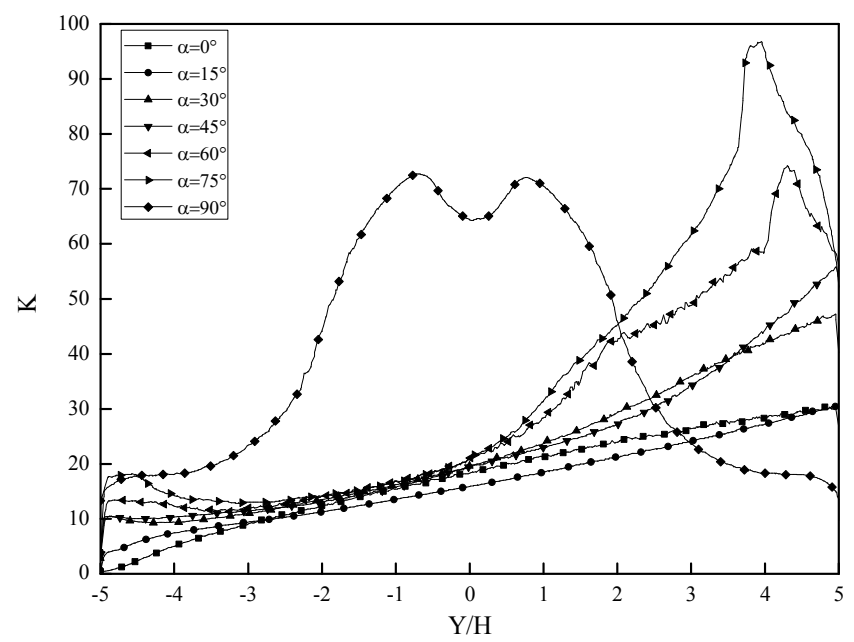

(a) next to the Wall $\mathrm{A}$

\section{Pollutant Distribution on the Vertical Cross Sections of the} Canyon

For each of the wind directions with $\alpha=90^{\circ}, 75^{\circ}, 60^{\circ}$ and $45^{\circ}$, at each of the five cross sections with $Y / H=-3.79$, $-1.26,0,1.26$ and 3.79 the pollutant concentrations are higher significantly on the Wall A side than on the Wall B side and the concentrations on the Wall A side decline with an increase of the height above the street floor (see Figs. 1013). This is because on each of the five vertical cross sections a CV transports the pollutants from the line sources towards the Wall A side. For the perpendicular wind, the concentration levels on the cross sections with $Y / H=-3.79$ and 3.79 (Figs. 13(a) and 13(e)) are much smaller than those on the cross sections with $Y / H=-1.26,0$ and 1.26 (Figs. 13(b)-13(d)). This is due to the establishment of the corner eddies, which leads to enhanced negative ACHs on Side 1 and Side 2 of the canyon (see Tables 1 and 2).

For the oblique wind with $\alpha=30^{\circ}$, the pollutants are accumulated on the Wall A side at each of the cross sections with $Y / H=-1.26,0,1.26$ and 3.79 (see Figs. 9(b)-9(e)), while at the section with $Y / H=-3.79$ the pollutant distribution is almost symmetric with respect to the central vertical line of the cross section (Fig. 9(a)) since the distorted vortex suppresses the dispersion of pollutants towards the upper part of the Wall A side.

For the oblique wind with $\alpha=15^{\circ}$, at each of the sections with $Y / H=-3.79$ and -1.26 the pollutant distribution is almost symmetric with respect to the central vertical line of the section (Figs. 8(a)-8(b)) while at each of the sections with $Y / H=0,1.26$ and 3.79 the pollutants are accumulated slightly on the Wall A side due to a very weak CV (Figs. 8(c)-8(e)).

For each of the oblique winds with $\alpha=15^{\circ}, 30^{\circ}, 45^{\circ}$, $60^{\circ}$ and $75^{\circ}$, it is clear that the pollution levels on the vertical cross sections increase towards the downstream end (see Figs. 8-12) due to the transport of pollutants by the street-axis parallel flow.

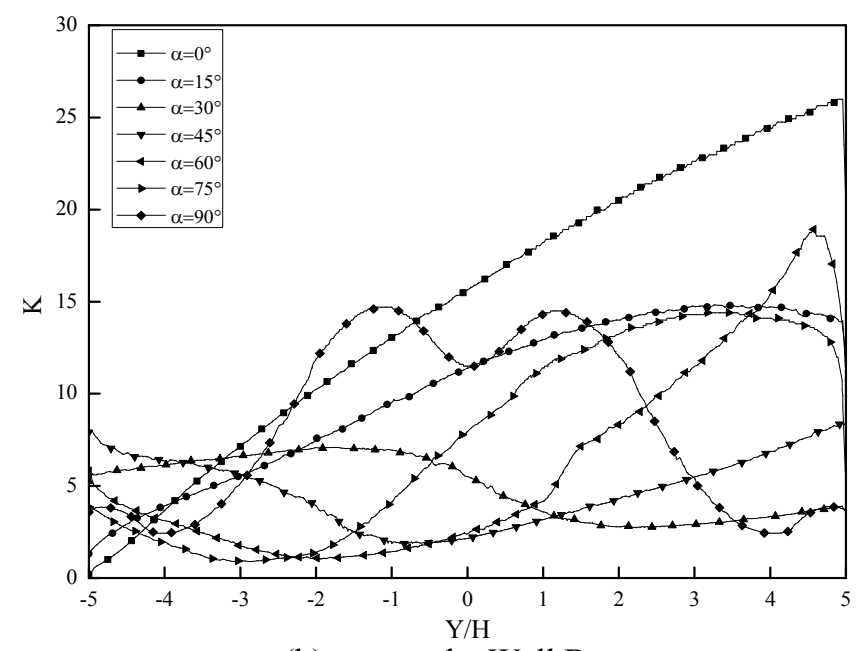

(b) next to the Wall B

Fig. 14. Near-ground $(z=0.01 \mathrm{~m})$ level profiles of dimensionless pollutant concentration next to the Walls A and B along the canyon length axis under seven different wind directions. 


\section{Pollutant Distribution on the Walls of the Canyon}

From a health point of view, much attention should be paid to pollutant distribution on the canyon walls since the indoor air quality is largely influenced by the pollutant concentration level of the outdoor air near building surfaces. The dimensionless pollutant concentration $K$ on the canyon walls under $\alpha=90^{\circ}, 45^{\circ}$ and $0^{\circ}$ (see Fig. 6) is analyzed briefly in the above CFD model validation
(Section 3.2). For the cases with $\alpha=15^{\circ}, 30^{\circ}, 60^{\circ}$ and $75^{\circ}$, the dimensionless pollutant concentration $K$ on the canyon walls is depicted in Fig. 15. The wall-average and wallmaximum concentrations are of particular interest in urban planning and in evaluation of urban air quality. Hence, Table 3 lists specifically the averaged and maximum dimensionless pollutant concentrations on Walls A and B under the seven wind directions. Based on Figs. 6 and 15,

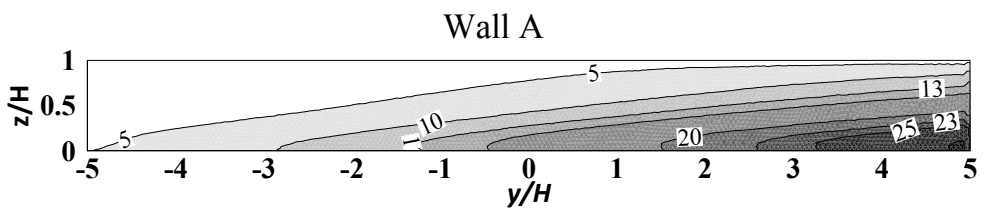

Wall B

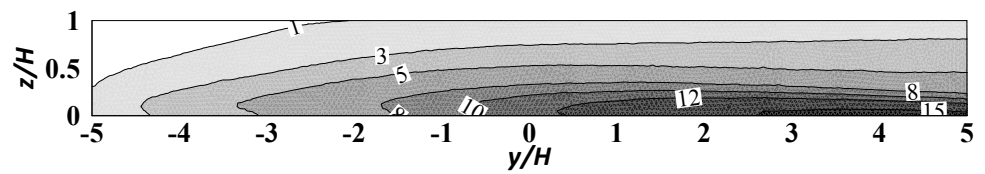

(a) $\alpha=15^{\circ}$

Wall A

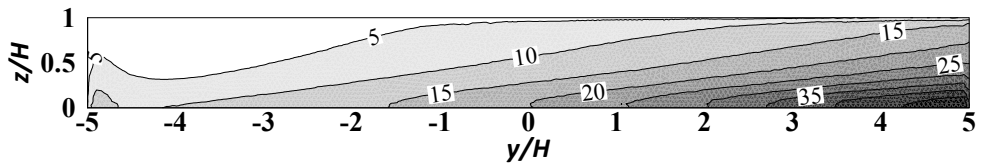

Wall B

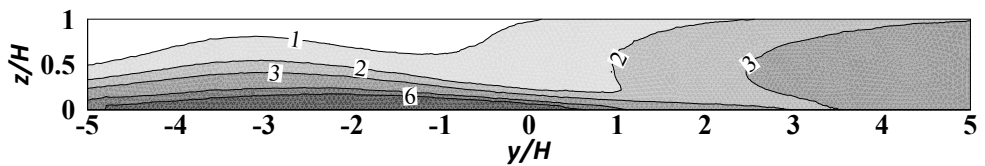

(b) $\alpha=30^{\circ}$

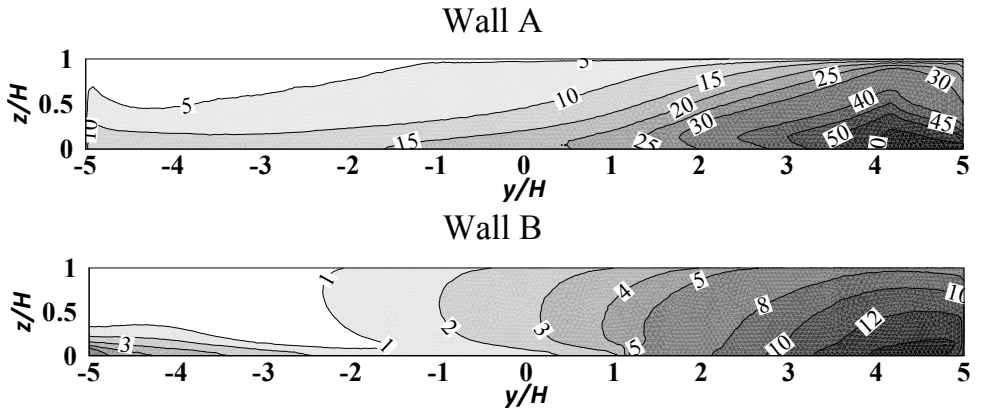

(c) $\alpha=60^{\circ}$

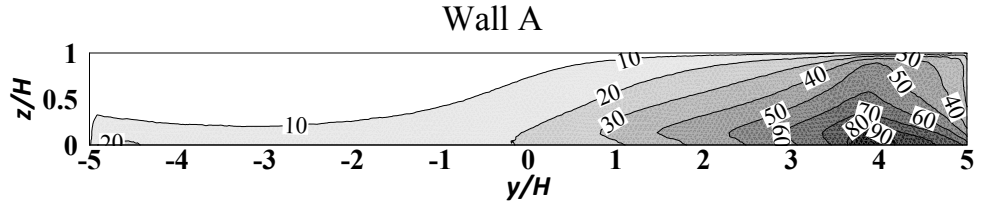

Wall B

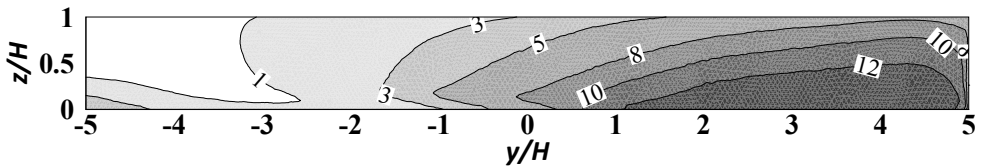

(d) $\alpha=75^{\circ}$

Fig. 15. Dimensionless pollutant concentrations $K$ at the Walls of the canyon with $L / H=10$ under four different wind directions. 
Table 3. Averaged and maximum dimensionless pollutant concentrations on Wall A and Wall B under seven different wind directions.

\begin{tabular}{|c|c|c|c|c|}
\hline \multirow{2}{*}{ Wind direction } & \multicolumn{2}{|c|}{ Averaged dimensionless concentration } & \multicolumn{2}{|c|}{ Maximum dimensionless concentration } \\
\hline & Wall A & Wall B & Wall A & Wall B \\
\hline $0^{\circ}$ & 7.40 & 7.39 & 29.07 & 29.08 \\
\hline $15^{\circ}$ & 9.46 & 4.98 & 30.50 & 15.64 \\
\hline $30^{\circ}$ & 13.25 & 2.69 & 48.84 & 7.48 \\
\hline $45^{\circ}$ & 14.22 & 2.62 & 56.73 & 7.24 \\
\hline $60^{\circ}$ & 17.28 & 4.39 & 74.82 & 18.00 \\
\hline $75^{\circ}$ & 23.49 & 5.96 & 101.30 & 14.78 \\
\hline $90^{\circ}$ & 28.25 & 7.08 & 73.13 & 14.85 \\
\hline
\end{tabular}

and Table 3, as well as the canyon flow characteristics revealed in Section 4.2, we can analyze systematically the effects of ambient wind direction on pollutant distribution patterns on the leeward-oriented and windward-oriented walls of the canyon.

For each of the cases with $\alpha=0^{\circ}$ and $90^{\circ}$, the features of pollutant concentration distributions on the canyon walls are revealed and analyzed in Section 3.2.

For each of the cases with $\alpha=75^{\circ}, 60^{\circ}, 45^{\circ}$ and $30^{\circ}$, the pollutant concentrations on Wall $\mathrm{A}$ are much higher than those on Wall B (see Figs. 6(b) and 15(b)-15(d)) since the street-axis perpendicular CV sweeps the pollutants from the line sources towards the Wall A side. For the case with $\alpha=15^{\circ}$, the pollutant concentrations on Wall A are only slightly higher than those on Wall B (see Fig. 15(a)) due to the action of a weak street-axis perpendicular CV.

On both walls under $\alpha=75^{\circ}$ and $60^{\circ}$ and on Wall A under $\alpha=45^{\circ}, 30^{\circ}$ and $15^{\circ}$, the concentration increases significantly towards the downstream end of the wall with the maximum pollutant concentration occurring next to the downstream edge of the wall at the pedestrian level (see Figs. 6(b) and 15(a)-15(d)). These characteristics of pollutant distribution are created due to the transport of pollutants by the street-axis parallel flow.

Comparing Fig. 6(c) with Figs. 15(a)-15(d) it is apparent that on Wall $\mathrm{A}$, the pollutant concentration level under $\alpha=0^{\circ}$ is the lowest among those under the seven wind directions examined. However, on Wall B the pollutant concentration level under $\alpha=0^{\circ}$ is larger than that under each of the wind directions with $\alpha=15^{\circ}, 30^{\circ}, 45^{\circ}, 60^{\circ}$ and $75^{\circ}$, and on the downstream part of Wall B the concentration level under $\alpha=0^{\circ}$ is larger obviously than that under $\alpha=90^{\circ}$.

From Table 3, it can be obtained clearly that 1) on Wall A the averaged concentration increases greatly with the angle $\alpha$ (e.g., the averaged concentration under $\alpha=90^{\circ}$ is 3.82 times that under $\alpha=0^{\circ}$ ), while on Wall $\mathrm{B}$ the averaged concentration is the highest under $\alpha=0^{\circ}$ (the averaged concentration under $\alpha=90^{\circ}$ is the second highest among those under the seven wind directions); 2) the averaged concentration on Wall $\mathrm{A}$ is significantly higher than that on Wall B for each of the oblique and perpendicular winds (the ratio of the averaged concentration on Wall $A$ to that on Wall B is 1.90 for $\alpha=15^{\circ}, 4.93$ for $\alpha=30^{\circ}, 5.43$ for $\alpha=45^{\circ}, 3.94$ for $\alpha=60^{\circ}, 3.94$ for $\alpha=75^{\circ}$ and 3.99 for $\alpha=90^{\circ}$ ); 3) the maximum concentration on Wall $\mathrm{A}$ is the highest under $\alpha=75^{\circ}$ but not under $\alpha=90^{\circ}$ (the maximum concentration under $\alpha=75^{\circ}$ is 1.35 times that under $\alpha=$ $90^{\circ}$ ), while the maximum concentration on Wall $\mathrm{B}$ is the highest under $\alpha=0^{\circ}$ and 4) the maximum concentration on Wall A is much higher than that on Wall B for each of the oblique and perpendicular wind directions (the ratio of the maximum concentration on Wall $\mathrm{A}$ to that on Wall $\mathrm{B}$ is 1.95 for $\alpha=15^{\circ}, 6.53$ for $\alpha=30^{\circ}, 7.84$ for $\alpha=45^{\circ}, 4.16$ for $\alpha=60^{\circ}, 6.85$ for $\alpha=75^{\circ}$ and 4.92 for $\alpha=90^{\circ}$ ).

\section{CONCLUSIONS}

This study has been conducted to investigate numerically the effects of the ambient wind direction on the flow and pollutant dispersion inside a long street canyon. Using the RANS equations with the standard $k-\varepsilon$ turbulence model and the advection-diffusion equation for the inert and passive chemical species, a 3D CFD model of the wind flow and traffic pollutant dispersion in a street canyon is first developed based on the FLUENT code and then validated against WT measured data. Then, the airflow and pollutant dispersion in an isolated canyon with $L / H=10$ and $W / H=1$ are simulated numerically for seven different wind directions, $\alpha=0^{\circ}, 15^{\circ}, 30^{\circ}, 45^{\circ}, 60^{\circ}, 75^{\circ}$ and $90^{\circ}$. The numerical results indicate that the wind flow pattern and traffic-related pollutant distribution inside a long isolated canyon are strongly dependent on the ambient wind direction. The main conclusions can be summarized as follows:

- The mean $(\overline{\mathrm{ACH}})$ and turbulence $\left(\mathrm{ACH}^{\prime}\right) \mathrm{ACHs}$ are close when $\alpha=0^{\circ}, 15^{\circ}, 30^{\circ}, 45^{\circ}$ and $60^{\circ}$, but the magnitude of $\mathrm{ACH}^{\prime}$ is significantly greater than that of $\overline{\mathrm{ACH}}$ when $\alpha=75^{\circ}$ and $90^{\circ}$. The total ACHs (ACH $=$ $\left.\overline{\mathrm{ACH}}+\mathrm{ACH}^{\prime}\right)$ are also relatively close when $\alpha=15^{\circ}$, $30^{\circ}, 45^{\circ}$ and $60^{\circ}$, with the strongest air exchange occurring when $\alpha=30^{\circ}$ and the weakest occurring when $\alpha=90^{\circ}$. Additionally, the removal and entry of air across the two sides of the canyon play an important role in canyon ventilation for all of the tested wind directions.

- The wind flow is mainly governed by a street-axis parallel flow when $\alpha=15^{\circ}$. When $\alpha=30^{\circ}$ and $45^{\circ}$, a corkscrew flow is established, and when $\alpha=60^{\circ}$ and $75^{\circ}$, an obvious corkscrew flow develops in the upstream part of the canyon while the flow in the downstream part is characterized by a CV structure. 
- Pollutant distributions along the canyon footpaths at human respiration height: On the footpath next to Wall A (the leeward-oriented wall), when $Y / H<2$, the concentration when $\alpha=90^{\circ}$ is higher (or even much higher) than for the other six wind directions, whereas when $Y / H>3$, the concentration when $\alpha=90^{\circ}$ is lower than when $\alpha=0^{\circ}$ and $15^{\circ}$ and much lower than when $\alpha=30^{\circ}, 45^{\circ}, 60^{\circ}$ and $75^{\circ}$. The highest concentration for the entire footpath next to Wall A occurs when $\alpha=75^{\circ}$, and the pollution level is much higher for this footpath than for the one next to Wall B (the windward-oriented wall) with oblique and perpendicular winds. For the footpath next to Wall $\mathrm{B}$, the highest concentration is observed when $\alpha=0^{\circ}$.

- Pollutant distributions on the canyon walls: For all of the tested oblique and perpendicular wind directions, the concentration is much higher on Wall $A$ than on Wall B; furthermore, with perpendicular wind, the concentrations on both walls remarkably decrease towards the wall ends. For all parallel and oblique wind directions, the concentration on Wall A increases significantly towards the downstream end of the wall, with the maximum concentration forming at the pedestrian level in a region next to the downstream edge. When, $\alpha=0^{\circ}, 15^{\circ}, 60^{\circ}$ and $75^{\circ}$, the pollutant concentration on Wall B also increases towards the downstream end of the wall, with the maximum concentration forming near the downstream edge at the pedestrian level. On Wall A, the lowest concentration for all seven wind directions is found when $\alpha=0^{\circ}$, whereas on Wall $\mathrm{B}$, the highest concentration for the parallel and oblique wind directions is found when $\alpha=$ $0^{\circ}$ (in the downstream part of Wall $\mathrm{B}$, the concentration is also higher when $\alpha=0^{\circ}$ than when $\alpha=90^{\circ}$ ). On Wall A, the wall-averaged concentration increases greatly with the wind angle $\alpha$, and the wall-maximum concentration is highest when $\alpha=75^{\circ}$ and lowest when $\alpha=0^{\circ}$. However, on Wall $\mathrm{B}$, both the wall-averaged and wall-maximum concentrations reach their maximums when $\alpha=0^{\circ}$. Finally, both the wall-averaged and wall-maximum concentrations are much higher on Wall A than on Wall B when the wind is oblique or perpendicular.

- The results of this study provide a basis for assessing/monitoring air quality within long isolated street canyons with various ambient wind directions.

This study is restricted to evaluating the distribution of pollutants on the canyon walls. Future investigations should assess the exposure using the daily building pollutant exposure $(E)(\mathrm{Ng}$ and Chau, 2014) and building intake fraction (IF) (Sha et al., 2018).

\section{ACKNOWLEDGEMENTS}

This work was financially supported by the Major State Research Development Program of China (Grant No. 2016YFC0402504) and the National Natural Science Foundation of China (Grant No. 51536006).

\section{REFERENCES}

Allegrini, J. (2018). A wind tunnel study on threedimensional buoyant flows in street canyons with different roof shapes and building lengths. Build. Environ. 143: 71-88.

ANSYS (2009). ANSYS FLUENT 12.0 User's Guide. ANSYS Inc., USA.

Cheng, W.C., Liu, C.H. and Leung, D.Y.C. (2009). On the comparison of the ventilation performance of street canyons of different aspect ratios and Richardson number. Build. Simul. 2: 53-61.

Chew, L.W., Glicksman, L.R. and Norford, L.K. (2018). Buoyant flows in street canyons: Comparison of RANS and LES at reduced and full scales. Build. Environ. 146: 77-87.

CODASC (2008). Concentration data of street canyons. Laboratory of Building- and Environmental Aerodynamics, IfH, Karlsruhe Institute of Technology, Germany.

Gromke, C. and Ruck, B. (2007). Influence of trees on the dispersion of pollutants in an urban street canyon Experimental investigation of the flow and concentration field. Atmos. Environ. 41: 3287-3302.

Gromke, C., Buccolieri, R., Sabatino, S.D. and Ruck, B. (2008). Dispersion study in a street canyon with tree planting by means of wind tunnel and numerical investigations - Evaluation of CFD data with experimental data. Atmos. Environ. 42: 8640-8650.

Gromke, C. and Ruck, B. (2012). Pollutant concentrations in street canyons of different aspect ratio with avenues of trees for various wind directions. Boundary Layer Meteorol. 144: 41-64.

Gromke, C. and Blocken, B. (2015). Influence of avenuetrees on air quality at the urban neighborhood scale. Part I: Quality assurance studies and turbulent Schmidt number analysis for RANS CFD simulations. Environ. Pollut. 196: 214-223.

Hang, J., Sandberg, M. and Li, Y.G. (2009). Effect of urban morphology on wind condition in idealized city models. Atmos. Environ. 43: 869-878.

Hang, J., Luo, Z.W., Sandberg, M. and Gong, J. (2013). Natural ventilation assessment in typical open and semiopen urban environments under various wind directions. Build. Environ. 70: 318-333.

Huang, Y.D., Hu, X.N. and Zeng, N.B. (2009). Impacts of wedge-shaped roofs on airflow and pollutant dispersion inside urban street canyons. Build. Environ. 12: 23352347.

Huang, Y.D., Xu, X., Liu, Z.Y., Deng, J.T. and Kim, C.N. (2016b). Impacts of shape and height of building roof on airflow and pollutant dispersion inside an isolated street canyon. Environ. Forensics. 17: 361-379.

Huang, Y.D., Zeng, N.B., Liu, Z.Y., Song, Y. and Xu, X. (2016a). Wind tunnel simulation of pollutant dispersion inside street canyons with galleries and multi-level flat roofs. J. Hydrodyn. 28: 801-810.

Jeanjean, A.P.R., Hinchliffe, G., McMullan, W.A., Monks, P.S. and Leigh, R.J. (2015). A CFD study on the 
effectiveness of trees to disperse road traffic emissions at a city scale. Atmos. Environ. 120: 1-14.

Karra, S., Malki-Epshtein, L. and Neophytou, M.K.A (2017). Air flow and pollution in a real, heterogeneous urban street canyon: A field and laboratory study. Atmos. Environ. 165: 370-384.

Kastner-Klein, P. and Plate, E.J. (1999). Wind-tunnel study of concentration fields in street canyons. Atmos. Environ. 33: 3973-3979.

Launder, B.E. and Spadling, D.B. (1974). The numerical computation of turbulent flows. Comput. Methods Appl. Mech. Eng. 3: 269-289.

Li, X.X., Liu, C.H. and Leung, D.Y.C. (2005). Development of a model for the determination of air exchange rates for the street canyon. Atmos. Environ. 39: 7285-7296.

Li, X.X., Britter, R.E. and Norford, L.K. (2015). Transport processes in and above two-dimensional urban street canyons under different stratification conditions: Results from numerical simulations. Environ. Fluid Mech. 15: 399-417.

Lin, M., Hang, J., Li, Y.G., Luo, Z.W. and Sandberg, M. (2014). Quantitative ventilation assessments of idealized urban canopy layers with various urban layouts and the same building packing density. Build. Environ. 79: 152167.

Liu, C.H., Leung, D.Y.C. and Barth, M.C. (2005). On the prediction of air and pollutant exchange rates in street canyons of different aspect ratios using large-eddy simulation. Atmos. Environ. 39: 1567-1574.

Moonen, P., Dorer, V. and Carmeliet, J. (2012). Effect of flow unsteadiness on the mean wind flow pattern in an idealized urban environment. J. Wind Eng. Ind. Aerodyn. 104: 389-396.

Nazarian, N. and Kleissl, J. (2016). Realistic solar heating in urban areas: Air exchange and street canyon ventilation. Build. Environ. 95: 75-93.

$\mathrm{Ng}, \mathrm{W}$. and Chau, C. (2014). A modeling investigation of the impact of street and building configurations on personal air pollutant exposure in isolated deep urban canyons. Sci. Total Environ. 468-469: 429-448.

Richmond-Bryant, J., Isukapalli, S.S. and Vallero, D.A. (2011). Air pollutant retention within a complex of urban street canyons. Atmos. Environ. 45: 7612-7618.

Salim, S.M., Buccolieri, R., Chan, A. and Sabatino, S.D. (2011a). Numerical simulation of atmospheric pollutant dispersion in an urban street canyon: Comparison between RANS and LES. J. Wind Eng. Ind. Aerodyn. 99: 103-113.

Salim, S.M., Cheah, S.C. and Chan, A. (2011b). Numerical simulation of dispersion in urban street canyons with avenue-like tree plantings: Comparison between RANS and LES. Build. Environ. 46: 1735-1746.

Sha, C.Y., Wang, X.M., Lin, Y.Y., Fan, Y.F., Chen, X. and Hang, J. (2018). The impact of urban open space and 'lift-up' building design on building intake fraction and daily pollutant exposure in idealized urban models. Sci. Total Environ. 633: 1314-1328.

Soulhac, L. and Salizzoni, P. (2010). Dispersion in a street canyon for a wind direction parallel to the street axis. $J$. Wind Eng. Ind. Aerodyn. 98: 903-910.

Tabor, G.R. and Baba-Ahmadi, M.H. (2010). Inlet conditions for large eddy simulation: A review. Comput. Fluids 39: 553-567.

Tominaga, Y., Mochida, A., Yoshie, R., Kataoka, H., Nozu, T., Yoshikawa, M. and Shirasawa, T. (2008). AIJ guidelines for practical applications of CFD to pedestrian wind environment around buildings. J. Wind Eng. Ind. Aerodyn. 96: 1749-1761.

Vardoulakis, S., Fisher, B.E.A., Pericleous, K. and Flesca, N.G. (2003). Modelling air quality in street canyons: A review. Atmos. Environ. 37: 155-182.

Wang, Q., Sandberg, M., Li, Y.Y., Yin, S. and Hang, J. (2017). Impacts of urban layouts and open space on urban ventilation evaluated by concentration decay method. Atmosphere 8: 169.

Yoshie, R., Mochida, A., Tominaga, Y., Kataoka, H., Harimoto, K., Nozu, T. and Shirasawa, T. (2007). Cooperative project for CFD prediction of pedestrian wind environment in the Architectural Institute of Japan. J. Wind Eng. Ind. Aerodyn. 95: 1551-1578.

Zhong, J., Cai, X.M. and Bloss, W.J. (2015). Modeling the dispersion and transport of reactive pollutants in a deep urban street canyon: Using large-eddy simulation. Environ. Pollut. 200: 42-52.

Received for review, December 15, 2018 Revised, December 21, 2018 Accepted, January 1, 2019 